\title{
Unraveling the Regulation of Hepatic Gluconeogenesis
}

\author{
Xueping Zhang, Shanshan Yang, Jinglu Chen and Zhiguang Su* \\ Molecular Medicine Research Center and National Clinical Research Center for Geriatrics, West China Hospital, State Key \\ Laboratory of Biotherapy, Sichuan University, Chengdu, China
}

Hepatic gluconeogenesis, de novo glucose synthesis from available precursors, plays a crucial role in maintaining glucose homeostasis to meet energy demands during prolonged starvation in animals. The abnormally increased rate of hepatic gluconeogenesis contributes to hyperglycemia in diabetes. Gluconeogenesis is regulated on multiple levels, such as hormonal secretion, gene transcription, and posttranslational modification. We review here the molecular mechanisms underlying the transcriptional regulation of gluconeogenesis in response to nutritional and hormonal changes. The nutrient state determines the hormone release, which instigates the signaling cascades in the liver to modulate the activities of various transcriptional factors

OPEN ACCESS

Edited by:

Åke Sjöholm,

Gävle Hospital, Sweden

Reviewed by:

Benoit Viollet,

Institut National de la Santé et de la Recherche Médicale (INSERM),

France

Juei-Tang Cheng,

Chang Jung Christian University,

Taiwan

Yan Lu,

Fudan University, China

*Correspondence:

Zhiguang Su

zhiguang.su@scu.edu.cn

Specialty section: This article was submitted to

Diabetes,

a section of the journal

Frontiers in Endocrinology

Received: 18 October 2018

Accepted: 20 December 2018

Published: 24 January 2019

Citation:

Zhang $X$, Yang S, Chen J and Su Z (2019) Unraveling the Regulation of

Hepatic Gluconeogenesis.

Front. Endocrinol. 9:802.

doi: 10.3389/fendo.2018.00802 through various post-translational modifications like phosphorylation, methylation, and acetylation. AMP-activated protein kinase (AMPK) can mediate the activities of some transcription factors, however its role in the regulation of gluconeogenesis remains uncertain. Metformin, a primary hypoglycemic agent of type 2 diabetes, ameliorates hyperglycemia predominantly through suppression of hepatic gluconeogenesis. Several molecular mechanisms have been proposed to be metformin's mode of action.

Keywords: gluconeogenesis, hormone, transcription factor, methylation, acetylation, AMPK, metformin

\section{INTRODUCTION}

Glucose functions as a primary fuel to active tissues like brain and blood cells in mammals and its blood levels are maintained within a relatively narrow range (1). The liver plays a crucial role in maintaining glucose homeostasis, as it is the main organ for glucose storage in the form of glycogen, as well as endogenous glucose production by glycogenolysis and gluconeogenesis. During short-term fasting periods, the liver produces and releases glucose mainly through glycogenolysis, which is the breakdown of glycogen to glucose. As the starvation time is prolonged, glycogen is depleted, and gluconeogenesis, that is de novo glucose synthesis from available precursors, becomes the main method of maintaining blood glucose levels. However, the abnormally increased rate of hepatic gluconeogenesis contributes to hyperglycemia of both type I and II diabetes. This underscores the importance of maintaining normal gluconeogenic rates to avoid disease pathophysiology. Therefore, identification of the molecular mechanisms regulating hepatic gluconeogenesis is crucial to the development of improved therapeutic strategies for the treatment of diabetes.

Gluconeogenesis is modulated by various external factors, such as nutrient and energy conditions, exercise, and stress reaction, through mediating the secretion and activity of certain molecules (2-4). The regulation of gluconeogenesis occurs on multiple levels, such as hormone secretion, gene transcription, and posttranslational modification. In response to the stimulation of external factors, hormone signals are promoted or inhibited, such as insulin, glucagon, 
and glucocorticoid, which in turn modulate the gluconeogenic pathways, regulating gene expression, and glucose production.

In this review, we would like to discuss the molecular mechanisms underlying the transcriptional regulation of gluconeogenesis in response to hormonal changes.

\section{GLUCONEOGENESIS AND ITS UNIQUE ENZYMES}

Gluconeogenesis is a process that transforms non-carbohydrate substrates (such as lactate, amino acids, and glycerol) into glucose (Figure 1). Both lactate and alanine are first converted into pyruvate, which then enters the mitochondrion and is carboxylated to oxaloacetate (OAA) by pyruvate carboxylase (PC). OAA is then reduced to malate to be shuttled to the cytoplasm where it is again reoxidized to OAA, which is decarboxylated and then phosphorylated to phosphoenolpyruvate (PEP) by cytosolic PEP carboxykinase (PEPCK-C). In addition to the cytosolic PEPCK, recent studies suggest that mitochondrial OAA can be directly converted to PEP by mitochondrial PEPCK (PEPCK-M) and then shuttled to the cytoplasm $(5,6)$. PEP then enters the gluconeogenic cycle. After several steps of reverse glycolysis, the yield fructose 1,6-bisphosphate $(\mathrm{F} 1,6 \mathrm{BP})$ is dephosphorylated by fructose 1,6-bisphosphatase (FBPase) to form fructose 6-phosphate, which is then converted to glucose6-phosphate (G6P) by phosphoglucoisomerase. Finally, G6P is converted to glucose via dephosphorylation by glucose-6phosphatase (G6Pase). Notably, other gluconeogenic amino acids, such as aspartate and glutamate, are converted by less direct routes into alanine or specific intermediates in the tricarboxylic acid (TCA) cycle for gluconeogenesis. Glycerol, released into plasma from adipose tissue, is taken up into the liver where it is converted to dihydroxyacetone phosphate (DHAP), which is then converted to glyceraldehyde-3phosphate (Glyceral-3-P) or F1,6BP, entering the gluconeogenic pathway.

Although gluconeogenesis is theoretically the reversal of glycolysis, there are three key irreversible glycolysis kinase reactions catalyzed by glucokinase (GK), phosphofructokinase-1 $(\mathrm{PFK}-1)$, and pyruvate kinase $(\mathrm{PK})(7)$, which are overcome by four unique gluconeogenic enzymes including PC, PEPCK, FBPase, and G6Pase (Figure 1). Given their importance in gluconeogenesis, the deregulation, or deficiency of these four enzymes can cause serious diseases, including type 2 diabetes in humans. For example, inhibition of hepatic PC not only decreases glycerol synthesis in adipose and liver, it also improves hepatic insulin signaling, while PC overexpression stimulates gluconeogenesis and leads to hyperglycemia (8); PEPCK deficiency contributes to a diverse level of persistent neonatal hypoglycemia and liver dysfunction (9); FBPase deficiency frequently causes hypoglycemia (10), while its overexpression leads to hyperglycemia and impaired insulin secretory function (11); G6Pase deficiency can lead to glycogen storage disease (GSD) with hypoglycemia, hepatomegaly, lactic acidemia, hyperuricemia, and hyperlipidemia (12).

\section{HORMONES CONTROL GLUCONEOGENESIS}

Hepatic gluconeogenesis is hormonally regulated, and numbers of hormones (e.g., glucagon and glucocorticoid) have known stimulatory effects (Figure 2). Of these hormones, glucagon seems to be the most important physiologically. However, only insulin plays a major inhibitory role. The rate of gluconeogenesis is determined by the balance between the stimulatory hormone and the inhibitory one.

\section{INSULIN AND GLUCAGON}

Insulin and glucagon are the most important hormones regulating hepatic gluconeogenesis. They demonstrated antagonistic effects on blood glucose levels. Under fasting or feeding, the blood circulating levels of the two hormones will change, subsequently affecting the expression of gluconeogenetic genes.

Insulin is a polypeptide hormone secreted by pancreatic $\beta$ cells, and its major physiological function is to regulate glucose transport, lipid synthesis, gluconeogenesis, and glycogen synthesis via the PI3K/Akt signaling pathway (13). Under feeding conditions, the raised blood glucose stimulates the secretion of insulin that binds to the insulin receptor (InsR) on the target organ, resulting in activation of InsR kinase and recruitment of insulin receptor substrates (IRS) (14), which in turn recruit and activate PI3K. The activated PI3K rapidly phosphorylates phosphatidylinositol 4,5-bisphosphate (PIP2) to generate the lipid second messenger phosphatidylinositol (3,4,5)-triphosphate (PIP3). The latter recruits $\mathrm{AKT}$ (also called protein kinase $\mathrm{B}, \mathrm{PKB}$ ) to the plasma membrane, where it is activated by phosphorylation and regulates glucose utilization through both the FoxO1 and CRTC2. The phosphorylation of FoxO1 and CRTC2 induces their nuclear exclusion and cytoplasmic retention through binding to 14-3-3 protein, suppressing gluconeogenic gene expression.

Glucagon is also a polypeptide hormone secreted by pancreatic $\alpha$ cells, and its primary function is to prevent hypoglycemia. After overnight fasting, the markedly increased glucagon released from the pancreas recognizes and then binds to the hepatic glucagon receptor (GCGR), which is a member of $G$ protein-coupled receptors characterized by being membrane-bound and G protein-coupled (15), forming a glucagon-receptor complex. Subsequently, GCGR undergoes a conformational change that can activate $G s \alpha$ ( $G$ protein). The activated Gs $\alpha$ in turn activates adenylate cyclase that generates the second messenger cAMP, and then cAMP stimulates cAMP-dependent protein kinase (PKA), which phosphorylates the cAMP-response element-binding protein (CREB) (16). Phosphorylated CREB binds to CRE and activates 


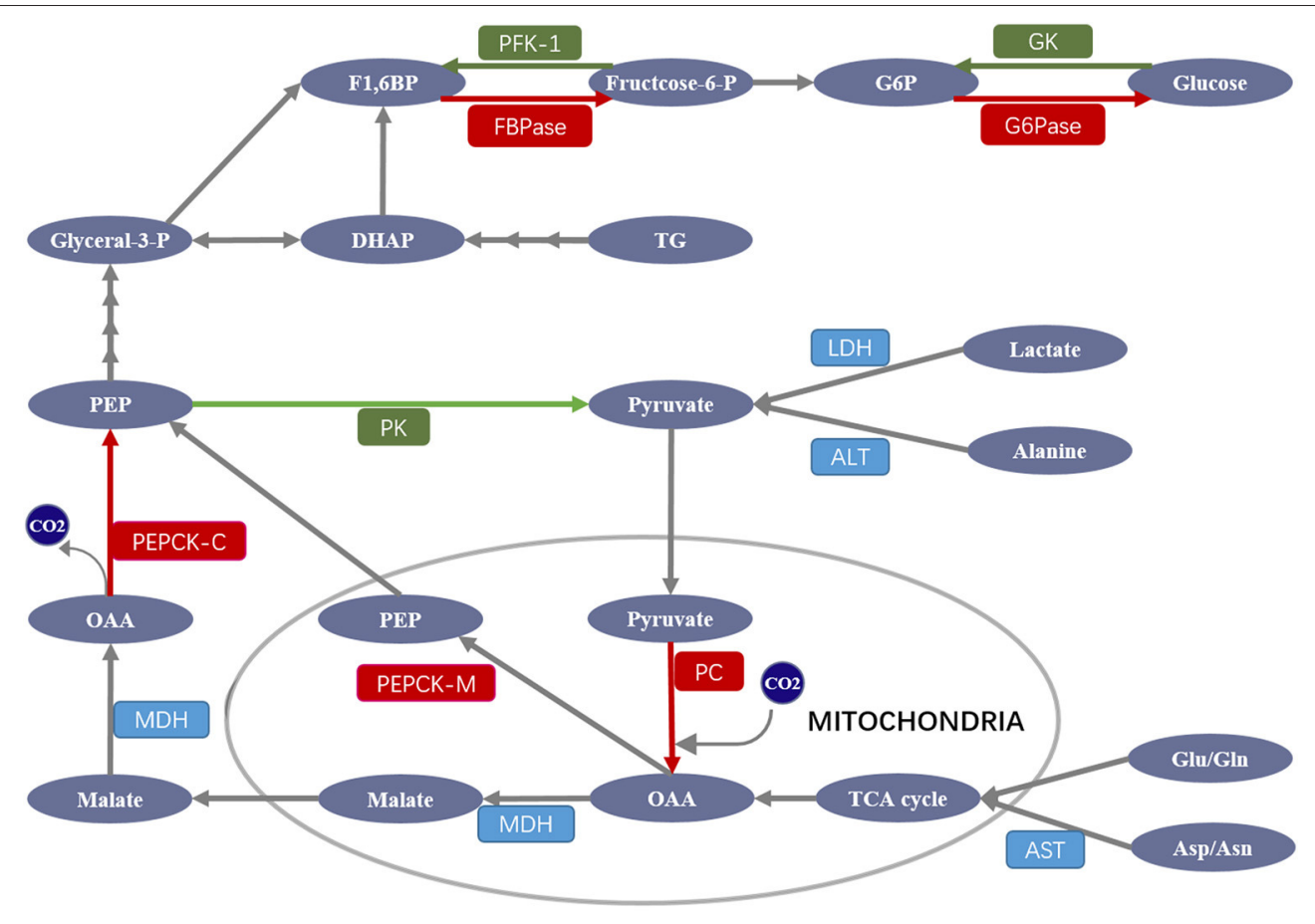

CYTOPLASM

FIGURE 1 | Schematic overview of major enzymes and metabolites involved in the regulation of gluconeogenesis. Pyruvate derived from lactate and alanine enters the mitochondrion, where it is carboxylated to oxaloacetate (OAA) by pyruvate carboxylase (PC). OAA is then reduced to malate to be shuttled to the cytoplasm where it is reoxidized to OAA, which is decarboxylated and then phosphorylated to phosphoenolpyruvate (PEP) by PEP carboxykinase (PEPCK). PEP then enters the gluconeogenic cycle. After several steps of reverse glycolysis, the yield fructose 1,6-bisphosphate (F1,6BP) is dephosphorylated by fructose 1,6-bisphosphatase (FBPase) to form fructose 6-phosphate, which is then converted to glucose-6-phosphate (G6P) by phosphoglucoisomerase. G6P is finally converted to glucose via dephosphorylation by glucose-6-phosphatase (G6Pase). Other gluconeogenic amino acids (Asp/Asn and Glu/Gln) are converted into alanine or specific intermediates in the tricarboxylic acid (TCA) cycle for gluconeogenesis. Glycerol is converted to dihydroxyacetone phosphate (DHAP), which is then converted to glyceraldehyde3-phosphate (Glyceral-3-P) or F1,6BP entering the gluconeogenic pathway. ALT, alanine aminotransaminase; AST, aspartate aminotransaminase; GK, glucokinase; $\mathrm{LDH}$, lactate dehydrogenase; $\mathrm{MDH}$, malate dehydrogenase. Gluconeogenic and glycolytic enzymes are highlighted in red and green, respectively.

the transcription of CRE-bearing genes (PEPCK and 6Pase gene).

\section{GLUCOCORTICOID}

Glucocorticoid is a kind of sterol hormone secreted by the zona fasciculata of the adrenal glands and its blood levels are under tight regulation by the hypothalamic-pituitaryadrenal axis. It is well-established that glucocorticoid itself can promote hepatic gluconeogenesis. Also, glucocorticoid is important for other hormones (e.g., glucagon) to promote gluconeogenesis in adrenalectomized mice (17). These mice exhibit reduced glucagon or cAMP-induced gluconeogenesis in fasting state, which however can be restored by treating mice with glucocorticoid. In addition, glucocorticoid can promote the generation of gluconeogenic amino acids in skeletal muscle and enhances the release of glycerol in adipose tissue, providing gluconeogenic precursors. On the whole, glucocorticoids play an important role in maintaining glucose homeostasis, its abnormal production results in distinct clinical disease phenotypes, such as Cushing's disease with hyperglycemia and Addison's disease with hypoglycemia (18).
Glucocorticoid functions through binding to intracellular glucocorticoid receptor (GR, also known as NR3C1a), which is a member of the nuclear hormone receptor superfamily. Without ligand binding, GR resides primarily in the cytoplasm in a complex with heat shock proteins (HSP 90 and 70) and co-chaperones Hsp40, p23 and others, leading the GR to preserve a low affinity state (19). Upon ligand binding, GR dissociates from the HSP90 chaperone complex and its DNA binding sites are exposed, then the GR-ligand complex enters the nucleus (20), where the complex either is recruited to specific glucocorticoid-responsive elements (GREs) on gene promoter or interacts with other transcriptional regulators, activating the expression of gluconeogenic genes including PC, PEPCK, FBPase, G6PC, and G6P.

\section{HORMONES IN HYPOTHALAMIC- PITUITARY-THYROID AXIS}

Thyrotro-pin-releasing hormone (TRH), secreted from the hypothalamus, acts upon the pituitary gland and binds to $G$ 


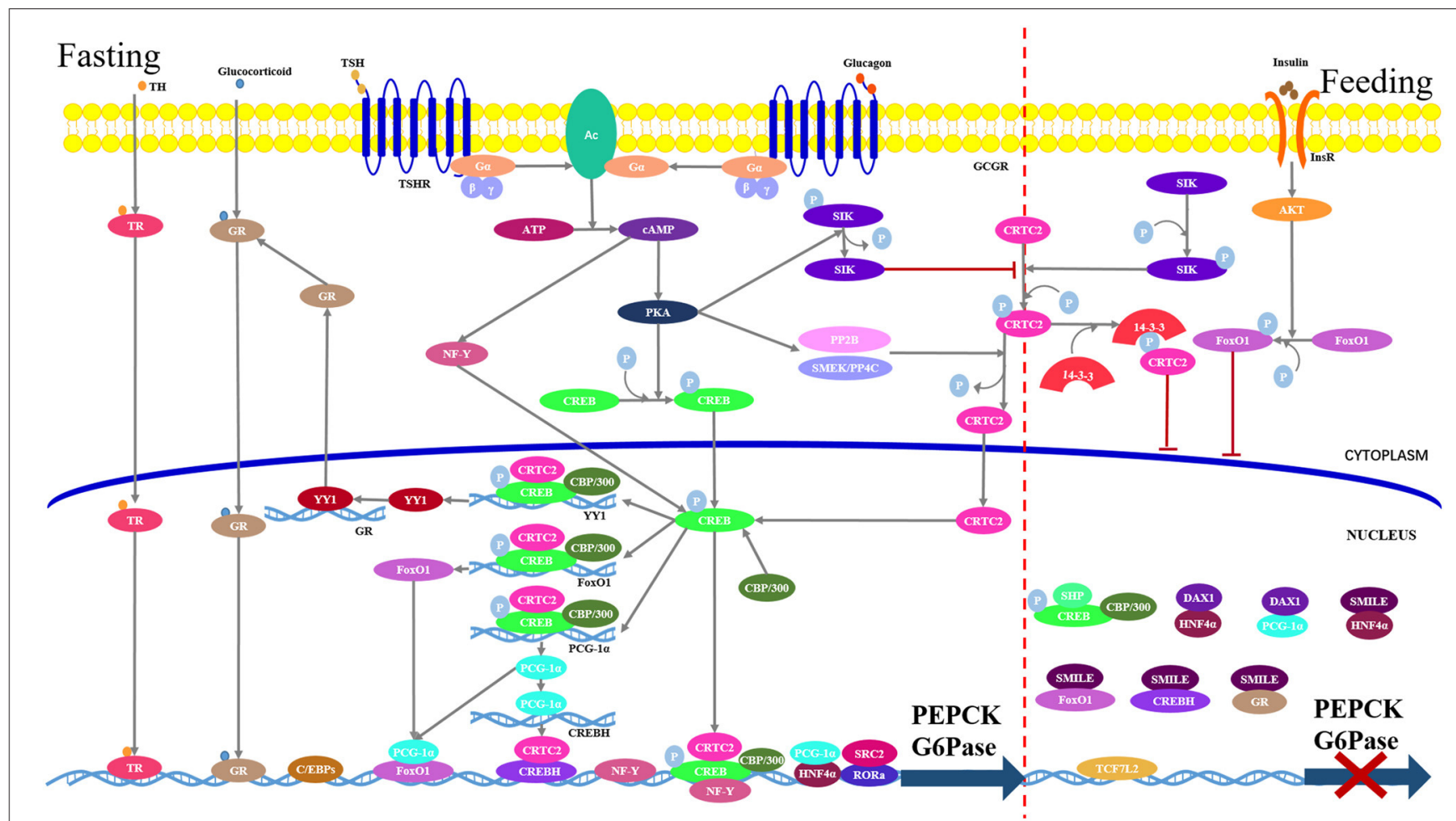

FIGURE 2 | Hepatic gluconeogenesis is regulated by various transcriptional factors in response to the hormonal changes. Under feeding conditions (right part), insulin-dependent activation of the AKT signaling stimulate FoxO1 phosphorylation and cytoplasmic retention. Meanwhile, CREB-regulated transcriptional coactivator-2 (CRTC2) undergoes rapid phosphorylation by salt-inducible kinases (SIKs), which results in its sequestration in the cytoplasm via interaction with 14-3-3 adaptor protein. Transcription factor 7-like 2 (TCF7L2) blocks gene expression through occupying transcriptional recognition sites. Small heterodimer partner-interacting leucine zipper protein (SMILL) and small heterodimer partner (SHP)/DAX1 directly bind to transcriptional factors to interfere with transcription. Under fasting conditions (left part), binding of glucagon or thyroid stimulating hormone (TSH) to its cognate G-protein-coupled receptor, respectively, stimulate adenylyl cyclase (AC), which converts ATP to CAMP. The cAMP in turn stimulates protein kinase A (PKA) to phosphorylate cAMP response element binding protein (CREB). Phosphorylated CREB transfers into the nucleus where it interacts with its coactivator CRTC2 and CBP/300 to form a complex, which binds to the CRE in the gluconeogenic promoters. CREB-CRTC-CBP/300 complex also binds to the promoters of PGC1-1 $\alpha$ and FoxO1 and stimulates their transcriptions. Nuclear factor-Y (NF-Y) induced by CAMP interacts with CREB to enhance the expression of PEPCK and G6Pase genes. Glucocorticoid and thyroid hormone (TH) bind gluconeogenic promoters in a hormone-receptor complex manner. Yin Yang 1 (YY1) induced by CREB promotes the GR transcription. C/EBP and HNF4 $\alpha$ directly bind to gene promoter. Steroid receptor coactivator 2 (SRC2) functions as a coactivator of receptor-related orphan receptor alpha (ROR $\alpha$ ), which directly binds to the promoters of PEPCK and G6Pase.

protein-coupled TRH receptors on the thyrotrope, resulting in an increase in intracellular cAMP, and subsequent thyroidstimulating hormone (TSH) release. Then TSH binds to a G protein-coupled TSH receptor (TSHR) on the thyroid follicular cell, stimulating the production, and release of thyroid hormone $(\mathrm{TH})$, and $\mathrm{TH}$ in turn regulates TRH/TSH. This is the fundamental pathway of the hypothalamic-pituitary-thyroid axis.

Studies show that the hormones TSH and TH are closely related to glycometabolism. TSH interacts with its receptor TSHR to activate the PKA via cAMP, PKA in turn inhibits the activation of SIK2 by dephosphorylating at Ser587. The dephospho-CRTC2 enters into the nucleus and interacts with CREB, promoting the expressions of PEPCK and G6Pase genes, and a subsequent increase in hepatic gluconeogenesis (21). In addition, TSH is also associated with hyperinsulinemia and insulin resistance (22). Therefore, the mechanism by which TSH regulates gluconeogenesis is not singular and may involve multiple molecular mechanisms. TH excessively produced by the thyroid gland promotes a hypermetabolic state characterized by increased resting energy expenditure and gluconeogenesis (23). Conversely, the reduced TH levels are associated with hypometabolism characterized by reduced resting energy expenditure and gluconeogenesis. Intracellular triiodothyronine (T3) is the active form of $\mathrm{TH}$ and its action is exerted primarily via binding to the $\mathrm{TH}$ receptors (TR). TRs are intracellular DNA-binding proteins that can bind to thyroid hormone-response element (TRE) in the promoter regions of target genes. The increased T3 binds to TR across the cell membrane and forms a hormone-TR complex in liver, then the complex directly binds to a TRE to promote the expression of genes encoding the gluconeogenic enzymes PEPCK and P6Gase (24). Additionally, T3-TR complex modulates gluconeogenesis gene expression via some other pathways as it can cross-talk with nuclear receptors (PPARs and LXR), SIRT1, FoxO1, and PCG- $1 \alpha$, which act as transcription factors for gluconeogenesis (24). 


\section{VASOPRESSIN}

Vasopressin, also named arginine vasopressin (AVP), is produced in hypothalamus and released by neurohypophysis in a condition of high plasma osmolality, low plasma volume, and low blood pressure (25). AVP is involved in diverse physiological functions, including the regulation of osmotic homeostasis, vasoconstriction, and ACTH release, which are mediated by three types of AVP receptors, designated as V1a, V1b, and V2. AVP also has a role in regulating glycometabolism; it not only stimulates hepatic gluconeogenesis and glycogenolysis by the $\mathrm{Vla}$ receptor, but also regulates the secretion of glucagon and insulin by Vlb receptor (26). The Vla receptor triggers $\mathrm{Ca}^{2+}$ influx, leading to a decreased concentration of mitochondrial $\mathrm{Ca}^{2+}$ and an increased PC activation in hepatocyte. Meanwhile, the Vlb receptor induces $\mathrm{Ca}^{2+}$ release from the endoplasmic reticulum (ER), which triggers exocytosis including insulin and glucagon in the pancreas. Under stringent extracellular $\mathrm{Ca}^{2+}$ deprivation, AVP still can increase the release of insulin and glucagon; the gluconeogenesis, however, is restrained. This suggests that the action of AVP is sensitive to extracellular $\mathrm{Ca}^{2+}$ and may be a $\mathrm{Ca}^{2+}$. independent pathway of VAP-induced insulin and glucagon release (27).

\section{BILE ACIDS}

Bile acids are known mainly as intestinal detergents for the absorption of dietary lipids and fat-soluble vitamins in the gut. In recent studies, bile acids have been proposed to participate in diverse physiologic processes, they also function as hormones or signaling molecules to regulate metabolism of lipids, glucose, and energy expenditure (28). Bile acids accomplish their regulatory functions mainly through two receptors: nuclear farnesoid $\mathrm{X}$ receptor (FXR) and G protein-coupled receptor TGR5. It has been revealed that bile acids and FXR upregulate the inhibitory nuclear receptor small heterodimer partner (SHP) in the liver $(29,30)$. As discussed in a later section, SHP functions as transcriptional co-repressor through interaction with other proteins to repress the transcription of gluconeogenic genes such as PEPCK, G6Pase, and FBPase, resulting in decreased glucose production. In addition, human bile acids act on FXR in ileal enterocytes to induce the expression of fibroblast growth factor (FGF)-19 (its mouse ortholog is FGF-15). FGF15/19 circulates to liver, where it binds to FGF receptor-4 (FGFR4) to inhibit the CREB-PGC-1 $\alpha$ signaling cascade, thereby repressing gluconeogenesis (31).

\section{TRANSCRIPTION FACTORS REGULATES GLUCONEOGENESIS}

Hormone release instigates signaling cascades in the liver to modulate activities of various transcription factors, which in turn control the expressions of key rate-limiting enzymes in the gluconeogenic pathway, specifically PEPCK and G6Pase (Figure 2).

\section{CAMP RESPONSE ELEMENT BINDING PROTEIN (CREB)}

CREB is a nuclear transcription factor binding to a conserved cAMP-response element (CRE) on gene promoter. CREB can be directly phosphorylated by protein kinase A (PKA) (16). Under fasting conditions, the increased secretion of pancreatic glucagon activates PKA, which in turn phosphorylates CREB, leading to an increased association of CREB with its co-activators CRTC2 and $\mathrm{CBP} / \mathrm{p} 300$ onto the chromatin. Subsequently, CREB directly drives the gluconeogenic gene transcription by binding to CRE on the promoter and enhances the expression of PEPCK and G6Pase, leading to increased hepatic gluconeogenesis (32). CREB is not only important in the direct transcriptional activation of gluconeogenic genes, but is also critical in modulating the activation of PGC- $1 \alpha$, which serves as a crucial transcriptional regulator for the activation of gluconeogenic genes during prolonged fasting (31). In addition, phosphorylation of CREBrecruiting p300/CBP increases FoxO1 gene expression, which in turn induces the expression of gluconeogenic genes (33).

\section{FORKHEAD BOX CLASS 01 (FOX01)}

FoxO proteins belong to a subgroup of the forkhead family of transcription factors that possess a conserved forkhead box-type DNA-binding domain. Four major FoxO proteins (FoxO1, 3, 4, and 6) are identified in mammals, and they are commonly regulated by the insulin/Akt signaling pathway. FOXO transcription factors modulate gene expression in stress resistance, metabolism, apoptosis, and longevity (34). Although FoxO proteins are highly related, only FoxO1 is the most direct transcriptional regulator of gluconeogenesis (35). During fasting state, $\mathrm{FoxO} 1$ is activated by dephosphorylation and translocated into the nucleus, leading to the transcriptional induction of G6Pase and PEPCK and an increased production of hepatic glucose (36). During feeding state, FoxO1 is negatively inhibited by the insulin signaling pathway. The increased secretion of pancreatic insulin activates PI3 kinase and the subsequent Akt, which in turn phosphorylates FoxO1 at Thr24, Ser253, and Ser316, and phosphorylation of FoxO1 exports from the nucleus, leading to a decreased occupancy of FoxO1 over the promoters of gluconeogenic genes and an attenuated gluconeogenesis (37). In the process of FoxO1 regulating gluconeogenesis, PGC- $1 \alpha$, and protein arginine methyltransferases 1 (PRMT1) act as coactivators and are crucial for the transcription of gluconeogenic genes $(38,39)$.

\section{CAMP RESPONSE ELEMENT-BINDING PROTEIN H (CREBH)}

CREBH belongs to ER-bound transcription factor families, and it is mainly expressed in the liver. CREBH was recently identified as an important physiological regulator of hepatic gluconeogenesis (40). During fasting or insulin-resistant state, the expression of CREBH is markedly induced by the PGC- $1 \alpha /$ GR complex, resulting in the accumulation of CREBH-N, which is an 
active nuclear form of CREBH. By cross-talking with its coactivator CRTC2, CREBH-N enhances hepatic gluconeogenesis by binding to a unique regulatory sequence in the promoter of the PEPCK or G6Pase genes (41). One recent study shows that the proteolytic cleavage and posttranslational acetylation modification of CREBH are regulated by the circadian clock (40), by which CREBH can regulate the rhythmic expression of the genes encoding the rate-limiting enzymes for glycogenolysis and gluconeogenesis, including liver glycogen phosphorylase, PEPCK, and G6Pase. In addition, the acetylation of CREBH at lys-294 controls CREBH-PPAR $\alpha$ interaction and synergy in regulating hepatic glucose metabolism in mice (40).

\section{CCAAT/ENHANCER-BINDING PROTEINS (C/EBPS)}

C/EBPs are key regulators of numerous cellular processes, including cell proliferation, differentiation, tumorigenesis, and gluconeogenesis and lipid synthesis (42). All C/EBPs (C/EBP $\alpha$, $\beta, \delta, \varepsilon$, and $\gamma$ ) consist of an $\mathrm{N}$-terminal transactivation domain (TAD), central regulatory regions, and a highly conserved Cterminus basic region leucine zipper (bZIP) domain. Targeted deletion of the $\mathrm{C} / \mathrm{EBP} \alpha$ gene in mice results in profound damage to liver structure and function and postnatal death because of hypoglycemia caused by defects in the hepatic gluconeogenesis and glycogen storage (43). Studies have shown that C/EBP $\alpha$ can be phosphorylated by p38 at serine 21 , and the phosphorylated $\mathrm{C} / \mathrm{EBP} \alpha$ exhibits increased transactivation activity to enhance PEPCK gene transcription (44). C/EBP $\beta$ can also bind to PEPCK promoter directly to activate gene expression, and $\mathrm{C} / \mathrm{EBP} \beta$ deficient mice show impaired hepatic glucose production (45). $\mathrm{C} / \mathrm{EBP} \beta$ activity is negatively regulated by AMP-activated protein kinase (AMPK), where activated AMPK suppresses C/EBP $\beta$ expression and inhibits PEPCK transcription in diabetes (46).

\section{NUCLEAR RECEPTORS (NRS)}

NRs are a superfamily of transcription factors. A typical nuclear receptor consists of a highly variable $\mathrm{NH} 2$-terminal $\mathrm{A} / \mathrm{B}$ domain that contains a transactivation function known as AF-1, a central conserved DNA binding domain (DBD or C domain), a short $\mathrm{D}$ domain that contains the nuclear location signal, a large conserved carboxyl-terminal $\mathrm{E}$ domain (LBD) that is responsible for the binding of cognate ligand or hormone and contains ligand-regulated transcriptional activation function 2 (AF-2) (47). NRs usually bind directly to the response elements of genes and regulate gene transcription. NRs exist as monomers, homodimers, or heterodimers.

Homodimeric NRs, such as glucocorticoid receptor (GR) and hepatocyte nuclear factor $4 \alpha$ (HNF4 $\alpha$ ), normally reside in the cytosol via interaction with chaperon proteins (e.g., HSP90 and HSP70). Upon binding ligand, the receptor disassociates from the chaperone and homodimerize, leading to the exposure of nuclear localization sequence and entry into the nucleus. HNF4a is hepatocyte-specific transcription factor mainly regulating hepatic differentiation (48), which is demonstrated to promote the expression of PEPCK and G6Pase via binding to the cis-elements in their promoters (49). TR4 can regulate the expression of gluconeogenic genes via binding to its novel responsive element (TR4RE) in the gene $5^{\prime}$-flanking region (50). Elimination of TR4 in hepatocytes significantly reduces PEPCK gene expression and glucose production in response to glucose depletion, while ectopic expression of TR4 increases PEPCK expression and hepatic glucose production in human and mouse hepatoma cells (33). NR4A contains three closely related receptors (Nur77, Nurr1, and NOR1), which are induced by multiple extracellular signals, including growth factors, apoptotic, and inflammatory signals and hormones in a cell type-specific manner (51). NR4A receptors not only are responsive to cAMP second messenger pathways in muscle and pituitary, but also are downstream mediators of the glucagon-CAMP-CREB axis in the control of glucose metabolism in liver (52).

Heterodimeric NRs (e.g., retinoic acid receptor, thyroid hormone-receptor, and the peroxisome proliferator-activated receptor $\alpha, \operatorname{PPAR} \alpha$ ) reside in the nucleus and form heterodimers with retinoid X receptor (RXR), which is generally bound to the target promoter through interactions with corepressor complexes NCoR and SMRT in the absence of ligand. Ligand binding results in the replacement of corepressors with coactivator complexes and facilitates gene transcription. PPAR $\alpha$, highly expressed in liver and brown adipose tissue, recognizes, and binds to specific DNA sequences AGGTCA (PPAR response elements) with the RXR. PPAR $\alpha$ has been identified as a direct activator of numerous gluconeogenic genes (53). Glucagon increases hepatic PPAR $\alpha$ activity, while insulin- and nutrient-sensitive pathways repress PPAR $\alpha$ activity through its co-repressor NCoR1 (54).

Monomeric NRs, such as retinoic acid receptor-related orphan receptor alpha $(\mathrm{ROR} \alpha)$, bind as monomers to halfsite response elements which typically consist of a consensus AGGTCA half-site. ROR $\alpha$ has been shown to directly bind to the promoters of PEPCK and G6Pase and regulates their transcriptions. Mice treated with ROR $\alpha$ antagonists or targeted deletion of the ROR $\alpha$ gene exhibit decreased PEPCK expression and glucose production. Similarly, the expression of G6Pase and PEPCK is suppressed in HepG2 cells overexpressing Rev-erb $\alpha$, the physiological repressor of $\operatorname{ROR} \alpha$. In contrast, silencing Rev-erb $\alpha$ significantly promotes G6Pase and PEPCK expression. Furthermore, there is evidence that steroid receptor coactivator 2 (SRC2) functions as a coactivator of ROR $\alpha$ to enhance the rate of transcription of G6Pase; both ROR $\alpha$ and SRC2 are required for the stimulatory effect of PGC-1 $\alpha$ on G6Pase transcription.

\section{OTHER TRANSCRIPTIONAL FACTORS}

Yin Yang 1 (YY1), belonging to the polycomb group protein family, is widely expressed in various tissues. YY1 binds to CCATNTT consensus sequences to activate or silence gene transcription via chromatin modification. During states of fasting or insulin resistance, YY1 transcriptionally upregulates GR expression, which then enhances the expression of gluconeogenic enzymes PEPCK and G6Pase, promoting hepatic glucose production (55). 
Nuclear factor-Y (NF-Y) is a trimeric protein complex composed by NF-YA, NF-YB, and NF-YC subunits, and it can specifically recognize and bind the CCAAT box. We recently observed that the hepatic NF-Y expression is markedly induced by cAMP, glucagon and fasting, and knockdown of NF-YA weakens gluconeogenic gene expression and glucose production in mice. NF-Y enhances the expressions of PEPCK and G6Pase either by binding to their promoters directly or interacting with CREB (56).

Transcription factor 7-like 2 (TCF7L2, also known as TCF4) is demonstrated as a strong candidate for type 2 diabetes in recent extensive genome-wide association studies (57). TCF7L2 plays a crucial role in suppressing hepatic gluconeogenesis. In the fed state, increased TCF7L2 binds to the promoters of the genes PEPCK and G6Pase, interfering the occupancy of both CREB and FoxO1 on their chromatin recognition sites (58). Under insulin-resistant conditions, the decreased expression of TCF7L2 in the nucleus may fail to inhibit CREB/FoxO1dependent gluconeogenesis (59). In addition, TCF7L2 mediates glucose homeostasis by enhancing glucagon-like peptide-1 (GLP1) secretion and GLP-1-dependent insulin secretion (60).

\section{COFACTORS REGULATING TRANSCRIPTION IN GLUCONEOGENESIS}

Transcriptional cofactors regulate gluconeogenesis by directly binding to transcriptional factors to either activate or inhibit transcriptions (Figure 2).

\section{PPAR $\gamma$ COACTIVATOR 1-ALPHA (PGC-1 $\alpha$ )}

PGC- $1 \alpha$ is a transcriptional coactivator that involves the regulation of energy metabolism. The expression of PGC- $1 \alpha$ is markedly induced in the liver upon prolonged fasting and in multiple diabetes animal models (61). Under fasting conditions, the increased PGC-1 $\alpha$ interacts with various gluconeogenic transcription factors such as FoxO1, GR, and HNF4 $\alpha$, enhancing their transactivating potentials and promoting the expression of gluconeogenic genes (62). Liver-specific PGC-1 $\alpha$ gene deletion studies (63) and acute RNAi-based PGC-1 $\alpha$ hepatic knockdown strategies (64) in mice lead to diminished expression of genes encoding gluconeogenic enzymes.

\section{CAMP-REGULATED TRANSCRIPTIONAL COACTIVATORS (CRTC2)}

CRTC2 is a member of the CRTC transcriptional coactivators family known as transducers of regulated CREB activity (TORC). There are three CRTC isoforms (CRTC1, 2, and 3) in mammals: CRTC1 is expressed predominantly in the brain, CRTC3 is expressed highly in adipose tissue, whereas CRTC2 is found mainly in liver. CRTCs contain an N-terminal CREB-binding domain, a central regulatory domain, and a negatively charged C-terminus TAD. The activity and cellular localization of CRTCs are phosphorylation-dependently regulated. Under feeding, liver kinase B1 (LKB1) constitutively activates salt-inducible kinases
(SIKs) through phosphorylation of a threonine residue in the activation loop of their kinase domain, leading to the subsequent phosphorylation of CRTCs (65), and phosphorylated CRTCs can bind to 14-3-3 protein and reside in the cytoplasm. Under fasting conditions, the activated serine/threonine phosphatases (e.g., PP2B or SMEK/PP4C) lead to rapid CRTC2 dephosphorylation. The dephosphorylated CRTC2 shuttles to the nucleus and interacts with chromatin-bound CREB, triggering gluconeogenic gene expression (66). Dephosphorylated CRTC2 also promotes increased histone $\mathrm{H} 3$ acetylation at Lys 9 (H3K9Ac), which subsequently potentiates CRTC2 occupancy over promoters of PEPCK, G6Pase, or PGC-1 $\alpha$ (67). In mammals, CRTC2 is also shown to directly bind to and coactivate additional bZIP transcription factors, such as $\mathrm{CREBH}$ and ATF6, regulating glucose homeostasis (41). Indeed, targeted deletion of the CRTC2 gene in mice attenuates the expression of gluconeogenic enzyme genes, resulting in a reduction in circulating blood glucose levels (68).

\section{P300 AND CREB BINDING PROTEIN (CBP)}

P300 and CBP are histone acetyltransferases transferring an acetyl group to lysine residue, and the acetylation level of non-histone proteins has been identified as a key mechanism for regulating hepatic gluconeogenic gene transcription (69). $\mathrm{P} 300 / \mathrm{CBP}$ is implicated in glucose metabolism due to its role as a transcriptional coactivator for CREB. Additionally, P300/CBP can promote FoxO1 expression by binding to the CREs in the proximal promoter region (70).

\section{SMALL HETERODIMER PARTNER-INTERACTING LEUCINE ZIPPER PROTEIN (SMILE)}

SMILE is a member of the CREB/ATF (activating transcription factor) family of bZIP transcription factors. Under feeding or insulin-resistant conditions, insulin can promote hepatic SMILE expression (71). SMILE competitively binds to nuclear receptors, such as estrogen-related receptor $\gamma, \mathrm{CREBH}, \mathrm{GR}$, constitutive androstane receptor, and $\mathrm{HNF} 4 \alpha$, and represses their transcriptional activities. SMILE can decrease the stimulatory effect of CREB/CRTC2 on hepatic gluconeogenesis (71).

\section{DAX-1 AND SMALL HETERODIMER PARTNER (SHP)}

DAX-1(also known as NR0B1) and SHP (also known as NR0B2) are members of an orphan nuclear receptor family of unknown endogenous ligands. However, unlike other nuclear receptors, both DAX and SHP lack a DNA-binding motif, and they primarily function as transcriptional corepressors through interaction with other proteins (72). SHP is predominantly found in the liver and represses the transcriptional activities of various nuclear receptors by inhibiting their occupancy over the cognate response elements in the promoters, such as GR, estrogen receptor, androgen receptor, steroidogenic factor 1 , 
and HNF4 $\alpha$. In addition, SHP can directly bind to CREB to block the association with CRTC2, leading to an inhibition of hepatic gluconeogenic gene expression (73). DAX-1 inhibits transcription via its LXXLL motifs and is mainly involved in steroidogenesis and reproductive development (72). There is evidence that DAX-1 can reduce hepatic gluconeogenesis by inhibiting the recruitment of other transcription factors or coactivators, such as HNF $4 \alpha$ and PGC- $1 \alpha$ onto the promoters of PEPCK and G6Pase (74).

\section{POST-TRANSLATIONAL MODIFICATIONS (PTMS) MODULATE GLUCONEOGENESIS}

PTMs including phosphorylation, (de)methylation, (de) acetylation, ADP-ribosylation and ubiquitination, and modulate gene transcription in a cell- and tissue-specific manner. The role of PTMs in the regulation of gluconeogenesis has received close attention. The aforementioned phosphorylation of transcriptional activators, such as FoxO1, CREB, and CRTC2, exemplifies a typical mechanism whereby PTMs directly regulate gluconeogenesis. In addition, Lysine acetylation and arginine methylation have been identified as evolutionarily conserved PTMs in gluconeogenic regulators and have emerged to play major roles in mediating gluconeogenesis.

\section{PHOSPHORYLATION BY AMP-ACTIVATED PROTEIN KINASE (AMPK)}

AMPK is an evolutionarily conserved serine/threonine heterotrimeric protein kinase, which consists of a catalytic $\alpha$-subunit and two regulatory subunits, $\beta$-subunits and $\gamma$ subunits. AMPK is activated when cellular energy levels are low, switching off ATP-consuming anabolic pathways and switching on ATP-generating catabolic processes. It has been reported that acute hepatic overexpression of a constitutively active form of AMPK $\alpha 2$ suppresses the expression of key hepatic gluconeogenic genes, G6Pase, and PEPCK, resulting in a depressed hepatic glucose output (75). Compound A-769662 is identified as a small-molecule AMPK activator, which has a robust anti-diabetic effect in ob/ob mice by impacting liver gluconeogenic pathways (76). AMPK can control gluconeogenic gene expression by promoting CRTC2 phosphorylation (77), and phosphorylated CTRC2 is sequestered in the cytoplasm and inhibits CREB-dependent transcriptions of PGCl $\alpha$ and gluconeogenic enzyme genes. In addition, as discussed in a later section, AMPK phosphorylates and nuclear exclude class II histone deacetylases (HDACs) that modulate the transcription of gluconeogenic genes (78).

Although many studies reported that AMPK acts as a regulator of hepatic gluconeogenesis, they have been performed by using non-specific AMPK activators or pharmacological compounds with AMPK-independent side effects. In addition to being an AMPK activator, A-769662 is found to inhibit $\mathrm{Na}+-\mathrm{K}+-$ ATPase in L6 skeletal muscle cells or non-proteolytic components of the $26 \mathrm{~S}$ proteasome by an AMPK-independent mechanism $(79,80)$. Moreover, a rich body of literature suggests that AMPK might not function as a regulator of hepatic gluconeogenesis (81-83), such as with compound PF-739, which is an AMPKspecific activator but has no impact on the endogenous glucose production rate in in vivo clamp studies (82). Therefore, the role of AMPK in the regulation of gluconeogenesis remains uncertain.

\section{METHYLATION BY PROTEIN ARGININE METHYLTRANSFERASES (PRMTS)}

PRMTs catalyze the transfer of methyl groups to arginine, and nine isoforms (PRMT1-9) consisting of three major types (type I-III) have been identified in mammals (84). Type I PRMTs including PRMT1, 3, 4, 6, and 8 usually function as transcriptional activators by promoting asymmetric dimethylation of arginine on histones or transcriptional regulators. Type II PRMTs comprising PRMT5, 7, and 9 generally function as transcriptional repressors by mediating symmetric dimethylation of arginine on histone. Type III PRMTs are less well-characterized in the control of transcription. Recent reports suggest that PRMT1, 4, 5, and 6 can control hepatic gluconeogenesis through specific modulation of FoxO1- and CREB-dependent transcriptional events (Figure 3).

PRMT1 catalyzes asymmetric methylation of FoxO1 at arginines 248 and 250, thereby repressing phosphorylation of the adjacent serine 253 (85), promoting its nuclear translocation and enhancing its chromatin occupancy over the promoters of gluconeogenic genes. Either acute knockdown or chronic haploinsufficiency of PRMT1 in mice reduces FoxO1-mediated gluconeogenesis, indicating that PRMT1 is critical in enhancing FoxO1 activity in the physiological context (86).

PRMT4, also known as coactivator-associated arginine methyltransferase 1, modulates hepatic gluconeogenesis through interaction with CREB in hepatocytes. PRMT4 can mediate asymmetric dimethylation of histone $\mathrm{H} 3$ at arginine 2 (H3R2), thereby promoting its acetylation by $\mathrm{CBP} / \mathrm{p} 300$, leading to an increased CREB-dependent transcription of gluconeogenic genes (87). However, there is evidence that PRMT4 can mediate arginine methylation in the KIX domain of CBP, leading its dissociation from CREB, resulting in an inhibition of CREBdependent transcription (88). Therefore, PRMT4-dependent regulation of gluconeogenesis requires further study.

PRMT5 regulates gluconeogenesis either as a coactivator of CREB or a corepressor of SHP. In fasting conditions, the elevated glucagon promotes the interaction of PRMT5 with CRTC2, by which PRMT5 is recruited to the gluconeogenic promoters and mediates symmetric dimethylation of H3R2, leading to enhanced chromatin accessibility at promoters, stimulating CREB phosphorylation, and gluconeogenic gene expression (89). In addition, PRMT5 can directly promote methylation of SHP at Arg57, which in turn recruits other chromatin-modifying repressive cofactors, such as Brm, Sin3A, G9a, and HDAC1, to repress gluconeogenic gene expression (90). Thus, further study is required to delineate whether the SHP activation compromises the CREB-dependent transcription.

PRMT6 can directly mediate asymmetric dimethylation of CTRC2 at multiple arginine residues, resulting in an enhanced 


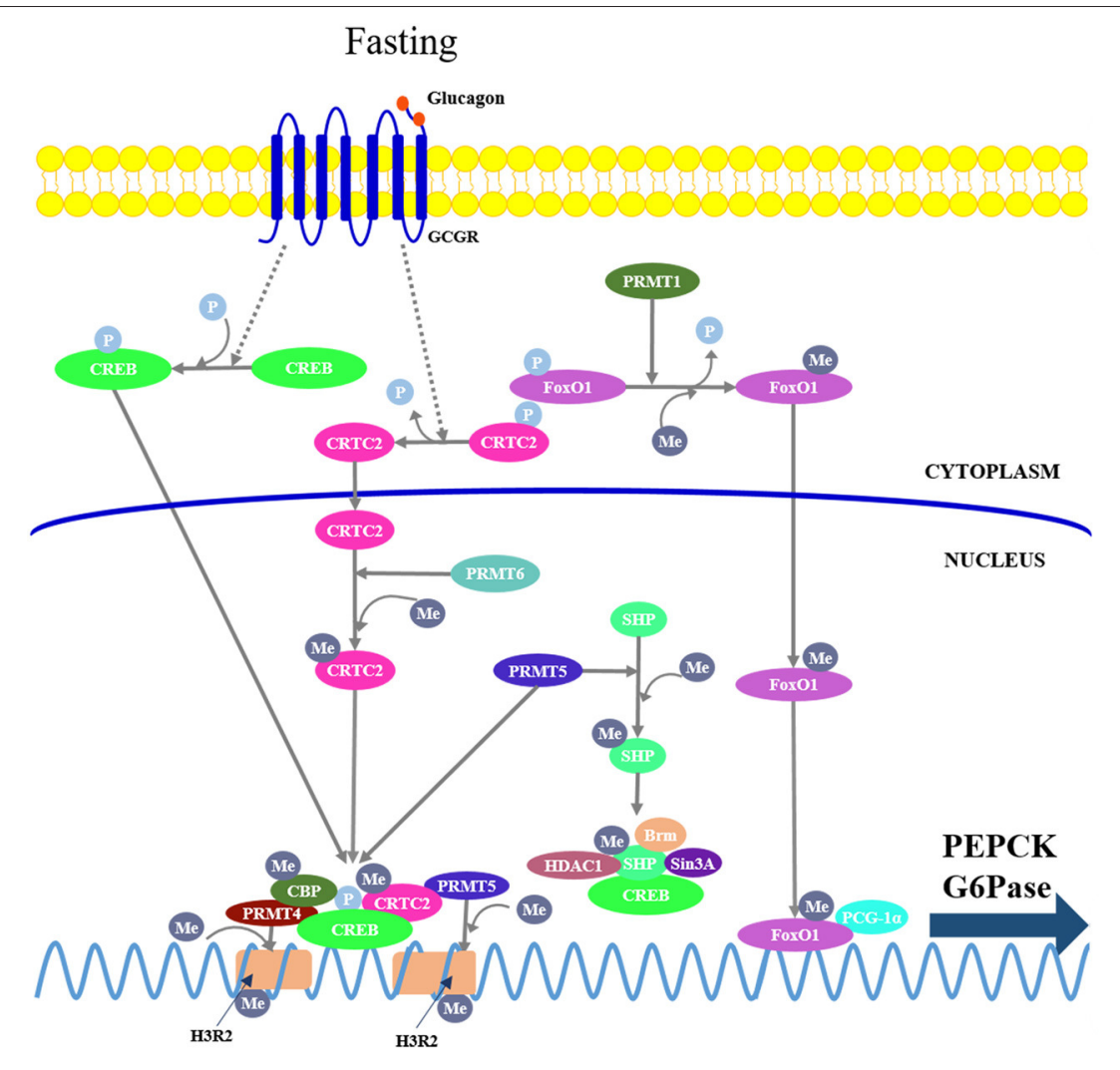

FIGURE 3 | Protein arginine methyltransferases (PRMTs) mediate hepatic gluconeogenesis. PRMT1 catalyzes asymmetric methylation of FoxO1, repressing phosphorylation, and promoting its nuclear translocation. PRMT4 and 5 are recruited to the gluconeogenic promoters by interacting with CREB and CRTC2, respectively, where they mediate symmetric dimethylation of histone $\mathrm{H} 3$ at arginine $2(\mathrm{H} 3 \mathrm{R} 2)$, leading to enhanced chromatin accessibility at promoters and promoting CREB-dependent transcription. On the other hand, PRMT4 also can mediate arginine methylation in the KIX domain of CBP, leading its dissociation from CREB; PRMT5 can directly promote arginine methylation of SHP, which in turn recruits other chromatin-modifying repressive cofactors (Brm, Sin3A, and HDAC1) to repress gluconeogenic gene expression. PRMT6 can directly mediate asymmetric dimethylation of CTRC2 to enhance the interaction between CRTC2 and CREB.

interaction between CRTC2 and CREB on gluconeogenic promoters (91).

\section{HISTONE DEMETHYLATION BY DEMETHYLASES}

Histone methylation, occurring on specific lysine and arginine residues in histones $\mathrm{H} 3$ and $\mathrm{H} 4$, has been associated with activated or repressed transcription. Lysine residues on histone tails can be mono-, di-, or trimethylated, while arginine residues can be mono and asymmetrically or symmetrically dimethylated. The site and degree of histone tail methylation have a distinct effect on gene regulation. For instance, histone $\mathrm{H} 3$ lysine-4 (H3K4) and H3K36 di- or trimethylation (Me2 or Me3) and $\mathrm{H} 3 \mathrm{~K} 27$ mono-methylation are positively correlated with transcriptional activity, whereas $\mathrm{H} 3 \mathrm{~K} 9$ and $\mathrm{H} 3 \mathrm{~K} 27 \mathrm{Me} 2$ and $\mathrm{Me} 3$ are found to mark the repressed genes (92).

Histone methylation is a dynamic and reversible process controlled by a balance between histone methyl-transferases and demethylases. Since the amine oxidase LSD1 (KDM1) is identified as the first histone lysine-specific demethylase, a number of histone demethylases have been identified, such as H3K9-specific demethylase JHDM2A (KDM3A), H3K27-specific demethylases UTX (KDM6A), and JMJD3 (KDM6B) (93). LSD1 histone demethylases require flavin adenine dinucleotide (FAD) as a co-factor (94). JHDM2A, UTX, and JMJD3 contain a JmjC domain that possesses demethylation activity, and these enzymes use $\mathrm{Fe}(\mathrm{II})$ and the intermediate metabolite a-ketoglutarate as co-factors to catalyze a hydroxylation-based demethylation (95).

Accumulated evidence has suggested that histone demethylation suppresses the expression of gluconeogenic genes and glucose production. For example, in one study in H4IIE rat hepatoma cells, Hall et al. observed that insulin induces demethylation of arginine-17 on histone $\mathrm{H} 3$ at promoters of PEPCK and G6Pase, which correlated with the disruption of the PEPCK and G6Pase gene transcription complex, resulting in the repression of gene transcription (96). In a study from Pan et al. H3K36 demethylase JHDM1a (KDM2A) was identified as a negative transcriptional regulator of gluconeogenesis (97). The authors demonstrated that the regulation of gluconeogenesis by JHDM1a requires demethylation activity, and JHDM1a actively removes dimethyl groups from histone $\mathrm{H} 3 \mathrm{~K} 36$ on the $\mathrm{C} / \mathrm{EBPa}$ locus and negatively regulates its expression, which in turn 
results in a decreased expression of gluconeogenic genes. In a recent study on human HepG2 cells, Pan et al. again reported that knockdown or pharmacological inhibition of LSD1 caused an increase of $\mathrm{H} 3 \mathrm{~K} 4$ dimethylation levels at promoters of FBP1 and G6Pase and an upregulation of their expression, leading to enhanced gluconeogenesis, and diminished intracellular glycogen content (98).

\section{ACETYLATION BY HISTONE ACETYLTRANSFERASES (HAT) AND DEACETYLATION BY HISTONE DEACETYLASES (HDACS)}

Acetylation of histone by HAT reduces the affinity between histone and DNA and allows transcription factors more accessible to DNA. Initially, acetylation is primarily identified on histone or chromatin-associated factors. Recent studies have shown that many transcriptional regulators are modulated by acetylation on lysine residues or that they are themselves acetyltransferase $(99,100)$. Therefore, protein acetylation plays a fundamental role in the regulation of gene expression. For example, in addition to being a CREB coactivator, P300 functions as PEPCK acetyltransferase to modulate gluconeogenesis. High-concentration glucose induces P300-catalyzed PEPCK acetylation, which stimulates its interaction with the E3 ubiquitin ligase UBR5, which ubiquitinates the acetylated PEPCK, leading to PEPCK degradation in a proteasome-dependent manner (101). As a result, gluconeogenesis is suppressed.

In contrast to HAT, HDACs remove acetyl groups, resulting in chromatin remodeling and transcription inhibition. In mammals, there are eighteen HDACs and they are divided into four classes (class I-IV) based on their sequence identity and catalytic activity (102). Class I HDACs (HDAC1-3 and 8) are yeast reduced potassium deficiency $3(\mathrm{Rpd} 3)$-like enzymes localized in the nucleus; Class II HDACs are yeast Hda1 proteinlike enzymes subdivided into class IIa (HDAC4, 5, 7, and 9) and IIb (HDAC6 and 10); Class III HDACs are yeast silent information regulator 2 (Sir2)-like enzymes and therefore are also called sirtuins (SIRTs), which are nicotinamide adenine dinucleotide (NAD)-dependent deacetylases. In mammals, there are seven sirtuins (SIRT1-7) localized in different subcellular regions. SIRT1 and 2 are found in both the nucleus and the cytoplasm, SIRT 3-5 are found predominantly in the mitochondria, whereas SIRT6 and 7 are localized mainly in the nucleus. Class IV includes HDAC11 localized in the nucleus. Numerous studies have demonstrated that HDACs are extensively involved into the regulation of glucose metabolism by controlling the activities of various gluconeogenic transcriptional factors (103) (Figure 4).

Class I HDACs increase the expression of nuclear receptor HNF $4 \alpha$ and the transcriptional activity of FoxO1 in hepatocytes, inducing PEPCK expression, and hepatic gluconeogenesis (104).

Class IIa HDACs play an important role in the regulation of hormone-induced FoxO (78). Under feeding conditions or metformin treatment, activated insulin/Akt, or LKB1AMPK signaling pathways induce phosphorylation of class IIa HDAC4/5/7 at Ser259 and Ser498, phosphorylated HDACs are excluded from the nucleus and bind to 14-3-3 adapter protein and reside in the cytoplasm. Under fasting conditions, an increased glucagon/cAMP/PKA signaling pathway induces class IIa HDAC dephosphorylation and nuclear translocation. In the nucleus, class IIa HDACs recruit Class I HDAC3 and form a complex that promotes FoxO1 deacetylation, enhancing FoxO1 DNA-binding and transcriptional induction of gluconeogenic genes (78). Indeed, similar to targeted hepatic FoxO1 deficiency in mice, loss of class IIa HDACs in liver results in lowered blood glucose and increased glycogen storage (105). In addition, class IIb HDAC6 is recently demonstrated to play an important role in glucocorticoid-mediated gluconeogenesis (106). HDAC6 deficiency in mice attenuates GR nuclear translocation, which is required for glucocorticoid response in relation to hepatic gene expression, resulting in a diminished expression of glucocorticoid-induced gluconeogenic genes and decreased hepatic glucose production.

Among Class III HDACs, SIRT1 is the most studied in gluconeogenesis. During fasting, SIRT1 mediates deacetylation and activation of transcription factors FoxO1 and PGC- $1 \alpha$, resulting in an elevated expression of gluconeogenic genes and hepatic glucose output (107). Additionally, SIRT1 has been shown to deacetylate and inactivate the hepatic signal transducer and activator of transcription-3 (STAT3) (108), which is acetylated by HAT P300 and in turn suppresses gluconeogenic enzyme expression. Accordingly, inhibition of SIRT1 expression in diabetic rats reduced blood glucose concentrations and hepatic expression of gluconeogenic genes as a result of increased acetylation of FoxO1, PGC-1 $\alpha$, and STAT3 (109). On the other hand, SIRT1 can downregulate hepatic expression of gluconeogenic genes and reduce gluconeogenesis during prolonged starvation; this is attributed to the deacetylation and subsequent ubiquitin-dependent degradation of CRTC2 (110). Additionally, there is evidence that metformin-induced AMPK activation increases the NAD+/NADH ratio and SIRT1 activity $(111,112)$, resulting in a reduction of gluconeogenesis in the liver.

Additionally, SIRT2, SIRT3, SIRT6, and SIRT7 have been implicated as potential regulators of blood glucose metabolism (101, 113-115). Therefore, sirtuins are promising pharmacological therapeutic targets for the treatment of insulin resistance and subsequent T2DM.

\section{HEPATIC GLUCONEOGENESIS IS A TARGET OF METFORMIN}

Metformin, a primary hypoglycemic agent for type 2 diabetes, ameliorates hyperglycemia predominantly through suppression of hepatic gluconeogenesis (116). Several molecular mechanisms have been proposed to be metformin's mode of action (Figure 5).

\section{METFORMIN SUPPRESSES HEPATIC GLUCONEOGENESIS IN AMPK-DEPENDENT WAYS}

Metformin-induced modulation of AMPK activity has been previously considered to be central to its physiological functions, including the inhibition of gluconeogenesis (117, 118). 


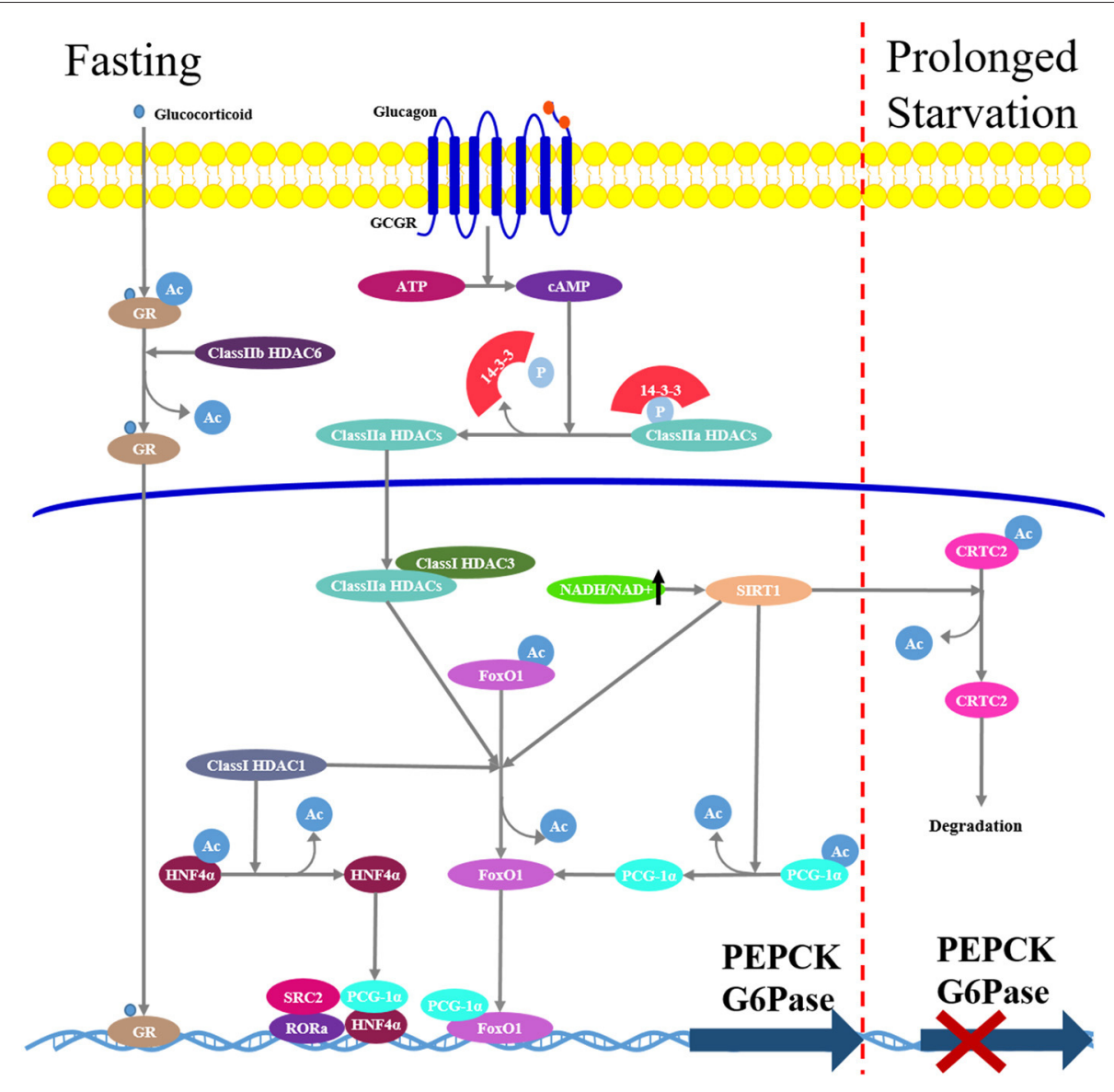

FIGURE 4 | Hepatic gluconeogenesis is modulated by histone deacetylases (HDACs). In fasting state, increased glucagon/cAMP/PKA signaling pathway induces class Ila HDACs dephosphorylation and nuclear translocation. In nucleus, they recruit class I HDAC3 and form a complex that promotes deacetylation and activation of FoxO1. Class IIb HDAC6 promotes glucocorticoid deacetylation and nuclear translocation. Class III HDACs SIRT1 mediates deacetylation and activation FoxO1 and PGC-1 $\alpha$. During prolonged starvation, Sirt1 can repress glucagon-induced gluconeogenesis through deacetylation and subsequent ubiquitin-dependent degradation of CRTC2.

Low metformin concentrations $(\leq 80 \mu \mathrm{M})$ can promote the phosphorylation of serine/threonine kinase 11 (STK11/LKB1), which in turn phosphorylates T172 on $\alpha 1$ subunit of AMPK and activates AMPK $(119,120)$, and genetic ablation of liver LKB1 eliminates the ability of metformin to activate AMPK in vivo. There is evidence that metformin could promote the assembly of a functional $\mathrm{AMPK}_{\alpha \beta \gamma}$ heterotrimeric complex, making it more easily phosphorylated at T172 of subunit $\alpha 1$ by upstream kinase LKB1, as well as hindering the dephosphorylation of the T172 by protein phosphatase (121). More recent evidence suggests that metformin can activate AMPK through promoting the formation of the vascular ATPase-Ragulator-AXIN/LKB1AMPK complex on the lysosome surface independent of energy state (122). It has been proposed that metformin-activated AMPK leads to phosphorylation-induced activation of the cyclic nucleotide phosphodiesterase 4B (PDE4B), which triggers cAMP breakdown to reduce the glucagon-stimulated rise in cAMP and PKA signaling (123). However, the role of AMPK in mediating the anti-hyperglycemic action of metformin remains controversial (81). It has been demonstrated that AMPK is neither sufficient nor necessary for acute inhibition of hepatic glucose production, which is supported by the observation that mice ablating AMPK catalytic subunits in the liver display blood glucose levels comparable with those of wild-type mice (81). Of significance, the repression of G6Pase expression in response to metformin treatment is preserved in mouse primary hepatocytes in which AMPK or LKB1 had been depleted (81). In order to help to reconciliate ongoing controversy and unify apparently conflicting data $(81,118)$, it has been hypothesized that AMPK might play an indirect role in the inhibition of hepatic glucose production as a consequence of AMPK-induced improvement of hepatic insulin sensitivity in obese diabetic mice $(81,124)$. AMPK is known as a critical regulator of lipogenesis (125), and chronic treatment of obese diabetic mice with metformin profoundly reduces hepatic steatosis and improves insulin resistance (126). Therefore, the glucose-lowering effect of metformin in obese diabetic mice might be due to the impact of AMPK activation on the reduction of hepatic fat content but 


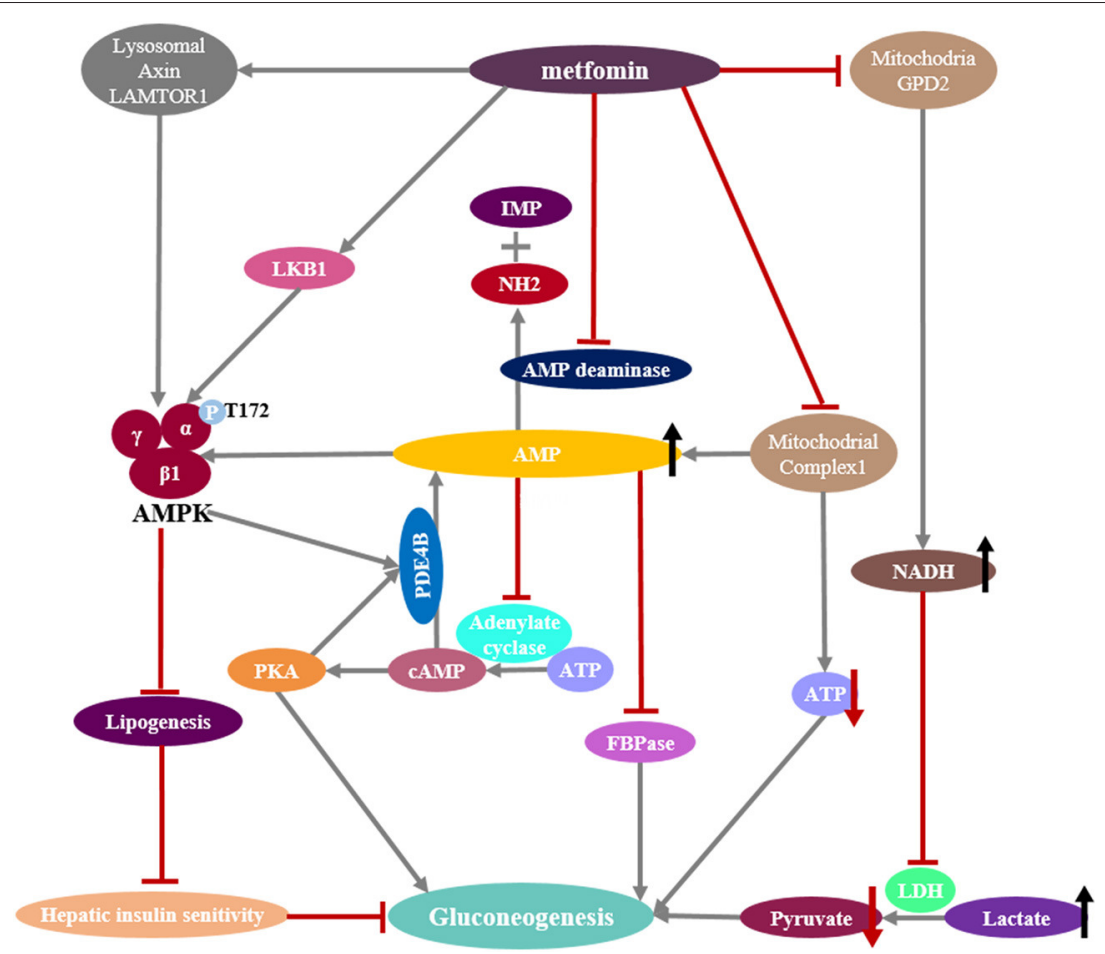

FIGURE 5 | Mechanisms of metformin suppressing hepatic gluconeogenesis. (Left) Pharmacologic metformin concentrations activates AMPK by promoting the formation of the AMPK heterotrimeric complex or the phosphorylation of serine/threonine kinase 11 (STK11/LKB1) or through a lysosomal mechanism requiring Axin and late endosomal/lysosomal adaptor, MAPK and mTOR activator 1 (LAMTOR1). Activated AMPK reduces hepatic lipogenesis and increases insulin sensitivity. Activated AMPK also phosphorylates and activates the CAMP-specific phosphodiesterase 4B (PDE4B), which triggers cAMP breakdown. (Middle) Suprapharmacologic metformin concentrations inhibit mitochondrial complex I, as does the inhibition of AMP deaminase, preventing mitochondrial ATP production and increasing cytoplasmic AMP levels. Reduction of cellular ATP levels leads to the suppression of hepatic gluconeogenesis that is an energy demanding process. Elevated AMP levels not only block the cAMP-PKA pathway by the inhibition of adenylyl cyclase activity, also inhibit the gluconeogenic rate-controlling enzyme FBPase and activate AMPK. (Right) Metformin inhibits mitochondrial glycerol 3-phosphate dehydrogenase (G3PDH, also named GPD2), resulting in an increase in cytosolic NADH levels and a suppression of lactate utilization and a consequent decreased gluconeogenesis.

not gluconeogenesis, leading to a subsequent increase in hepatic insulin sensitivity and ultimately to the normalization of blood glucose levels.

\section{METFORMIN SUPPRESSES HEPATIC GLUCONEOGENESIS IN AMPK-INDEPENDENT WAYS}

Mechanistic studies suggest that the primary site of metformin action appears to be the respiratory chain complex I (Figure 5), which catalyzes the transfer of two electrons from $\mathrm{NADH}$ to lipid-soluble ubiquinone and translocation of four protons $\left(\mathrm{H}^{+}\right)$from the matrix to the mitochondrial intermembrane space to generate a proton gradient that is the energy source in ATP synthesis. Metformin could decrease intracellular ATP production through the disruption of mitochondrial complex I (127), leading to a change in the ratio of AMP or ADP/ATP in an AMPK-independent pathway (81). Since gluconeogenesis is an energy-consuming process, it has been proposed that reduction of cellular ATP levels by metformin will lead to the suppression of hepatic gluconeogenesis (81). However, the ratio of $\mathrm{AMP}$ or $\mathrm{ADP} / \mathrm{ATP}$ is affected only at $>250 \mu \mathrm{M}$ metformin $(81,119)$, which is unreachable in the portal vein at pharmacologic metformin concentrations $(80 \mu \mathrm{M})$. Moreover, the cellular ADP/ATP ratio is not changed after metformin treatment in some studies (128). Recent study also supports the notion that metformin increases cellular AMP levels through the inhibition of AMP deaminase (129), which converts AMP to inosine monophosphate (IMP) and releases an ammonia molecule. The accumulated cellular AMP after metformin treatment results in the inhibition of adenylate cyclase, in turn reducing cAMP levels, leading to decreased PKA kinase activity and the inhibition of glucagon-dependent gluconeogenesis (130). More recently, metformin-induced increases in AMP concentrations have been shown to allosterically inhibit FBPase (124), which is a key rate-controlling enzyme in the gluconeogenic pathway by catalyzing the irreversible hydrolysis of F1,6BP to fructose-6phosphate (Figure 1). Individuals with FBP1 deficiency present with hypoglycemia and metabolic acidosis due to impaired gluconeogenesis.

Recently, an additional mitochondrial target implicated in metformin has been proposed $(131,132)$. Metformin is reported 
to suppress mitochondrial glycerophosphate dehydrogenase (mGPDH), which is a key component of the $\alpha$-glycerophosphate shuttle, resulting in an inhibition of $\mathrm{NADH}$ shuttle from the cytoplasm into mitochondria and the conversion of lactate to pyruvate. Subsequently, the hepatic gluconeogenesis from lactate is inhibited (Figure 5). This metformin pathway may be important in diabetes patients with high levels of serum lactate. However, as discussed in an editorial (133), the malateaspartate shuttle is quantitatively much more important than the glycerophosphate shuttle in hepatocytes; thus, disruption of the glycerophosphate shuttle alone may not be enough to sustain impact on gluconeogenesis unless the mitochondrial membrane potential also becomes suppressed.

\section{CONCLUSION}

Hepatic gluconeogenesis is largely controlled by transcriptional regulation of key rate-limiting enzymes, and these transcription regulators are mediated by hormonal signals in response to nutritional changes during the starvation-feeding cycle. Significant progress has been made to understand the expression regulation of gluconeogenic enzymes PEPCK and G6Pase by various transcriptional factors and their posttranslational modifications including phosphorylation, methylation and acetylation. Although PEPCK and G6Pase are regarded as the central operators of gluconeogenesis, recent investigations question their roles in the regulation of gluconeogenesis. Targeted deletion of the PEPCK gene in mice only led to a $40 \%$ reduction in gluconeogenic flux despite a $90 \%$ reduction in hepatic PEPCK expression (123). Moreover, although the expression of PEPCK and G6Pase are not increased in the poorly-controlled type 2 patients, their fasting blood glucose concentrations are dramatically elevated (122). These studies suggest that PEPCK and G6Pase may not be the most important regulators of gluconeogenesis. In addition to PEPCK and G6Pase, PC, and FBPase are also unique enzymes in gluconeogenesis; however, the regulation of their activities and expressions are

\section{REFERENCES}

1. Petersen MC, Vatner DF, Shulman GI. Regulation of hepatic glucose metabolism in health and disease. Nat Rev Endocrinol. (2017) 13:572-87. doi: $10.1038 /$ nrendo. 2017.80

2. Knudsen JG, Bienso RS, Hassing HA, Jakobsen AH, Pilegaard $H$. Exercise-induced regulation of key factors in substrate choice and gluconeogenesis in mouse liver. Mol Cell Biochem. (2015) 403:209-17. doi: 10.1007/s11010-015-2351-0

3. Shi S, Ansari T, Mcguinness OP, Wasserman DH, Johnson CH. Circadian disruption leads to insulin resistance and obesity. Curr Biol. (2013) 23:37281. doi: 10.1016/j.cub.2013.01.048

4. Sepakishi DM, Katsnelson G, Bikopoulos G, Iqbal A, Ceddia RB. Cold acclimation reduces hepatic protein Kinase B and AMP-activated protein kinase phosphorylation and increases gluconeogenesis in rats. Physiol Rep. (2018) 6:e13592. doi: 10.14814/phy2.13592

5. Mendez-Lucas A, Duarte JA, Sunny NE, Satapati S, He T, Fu X, et al. PEPCK-M expression in mouse liver potentiates, not replaces, PEPCK-C mediated gluconeogenesis. J Hepatol. (2013) 59:105-13. doi: 10.1016/j.jhep.2013.02.020 rarely studied. Understanding the transcriptional regulation of PC and FBPase and their effects on gluconeogenesis should be the focus of future work.

Hepatic gluconeogenesis is a complex and genetically heterogeneous process modulated on multiple levels (1). Although there are growing data on the identification of transcription control of gluconeogenesis, which is a relatively slow process, limited information is available regarding the acute control of gluconeogenesis. Indeed, hepatic gluconeogenesis is suppressed rapidly following the intravenous administration of either galegine or metformin in rat; this is inconsistent with that of transcriptional regulation mechanisms. Regulation of hepatic gluconeogenesis can also be controlled through the regulation of substrate supply and allosteric regulation of enzyme activity. For example, glucagon can stimulate hepatic gluconeogenesis by inhibiting the liver-specific PK and induces the phosphorylation of the fructose-2,6-bisphosphatase 2 (PFK2). Phosphorylated PFK2 functions as phosphatase to decrease the production of fructose-2,6-bisphosphate, resulting in an inhibitory attenuation to the gluconeogenic enzyme FBPase. Additionally, phosphorylated PFK2 suppresses GK by promoting its nuclear translocation. Overall, identifying key regulators that control gluconeogenesis could provide novel ways to treat type 2 diabetes.

\section{AUTHOR CONTRIBUTIONS}

All authors listed have made a substantial, direct and intellectual contribution to the work, and approved it for publication.

\section{ACKNOWLEDGMENTS}

This study was provided by the National Natural Science Foundation of China (Nos. 81770814 and 31501016) and Sichuan Province Science and Technology Support Program (Nos. 2015SZ0140 and 2018SZ0171).
6. Stark R, Guebre-Egziabher F, Zhao X, Feriod C, Dong J, Alves TC, et al. A role for mitochondrial phosphoenolpyruvate carboxykinase (PEPCK-M) in the regulation of hepatic gluconeogenesis. J Biol Chem. (2014) 289:7257-63. doi: 10.1074/jbc.C113.544759

7. Pilkis SJ, Granner DK. Molecular physiology of the regulation of hepatic gluconeogenesis and glycolysis. Annu Rev Physiol. (1992) 54:885-909. doi: 10.1146/annurev.ph.54.030192.004321

8. Kumashiro N, Beddow SA, Vatner DF, Majumdar SK, Cantley JL, Guebreegziabher F, et al.Targeting pyruvate carboxylase reduces gluconeogenesis and adiposity and improves insulin resistance. Diabetes (2013) 62:2183-94. doi: 10.2337/db12-1311

9. Vidnes J, Søvik O. Gluconeogenesis in infancy and childhood III. Deficiency of the extramitochondrial Form of hepatic phosphoenolpyruvate carboxykinase in a case of persistent neonatal hypoglycaemia. Acta Paediatr. (2010) 65:307-12. doi: 10.1111/j.1651-2227.1976.tb04890.x

10. Moey LH, Abdul Azize NA, Yakob Y, Leong HY, Keng WT, Chen BC, et al. Fructose-1,6-bisphosphatase deficiency as a cause of recurrent hypoglycemia and metabolic acidosis: clinical and molecular findings in Malaysian patients. Pediatr Neonatol. (2017) 59:397-403. doi: 10.1016/j.pedneo.2017.11.006 
11. Kebede M, Favaloro J, Je Laybutt D, Shaw M, Wong N, Fam B, et al. Fructose1,6-bisphosphatase overexpression in pancreatic beta-cells results in reduced insulin secretion: a new mechanism for fat-induced impairment of beta-cell function. Diabetes (2008) 57:1887-95. doi: 10.2337/db07-1326

12. Chou JY, Jun HS, Mansfield BC. Glycogen storage disease type I and G6Pase|[beta]| deficiency: etiology and therapy. Nat Rev Endocrinol. (2010) 6:67688. doi: $10.1038 /$ nrendo.2010.189

13. De MP. Insulin and its receptor: structure, function and evolution. Bioessays (2010) 26:1351-62. doi: 10.1002/bies.20151

14. White MF. The IRS-signalling system: a network of docking proteins that mediate insulin action. Mol Cell Biochem. (1998) 182:3-11. doi: 10.1023/A:1006806722619

15. Lagerstrom MC, Schioth HB. Structural diversity of G protein-coupled receptors and significance for drug discovery. Nat Rev Drug Discov. (2008) 7:339-57. doi: 10.1038/nrd2518

16. Gonzalez GA, Montminy MR. Cyclic AMP stimulates somatostatin gene transcription by phosphorylation of CREB at serine 133. Cell (1989) 59:67580. doi: 10.1016/0092-8674(89)90013-5

17. Kuo T, McQueen A, Chen TC, Wang JC. Regulation of glucose homeostasis by glucocorticoids. Adv Exp Med Biol. (2015) 872:99-126. doi: 10.1007/978-1-4939-2895-8_5

18. Rose AJ, Vegiopoulos A, Herzig S. Role of glucocorticoids and the glucocorticoid receptor in metabolism: insights from genetic manipulations. J Steroid Biochem Mol Biol. (2010) 122:10-20. doi: 10.1016/j.jsbmb.2010.02.010

19. Stavreva DA, Wiench M, John S, Conwaycampbell BL, Mckenna MA, Pooley $\mathrm{JR}$, et al. Ultradian hormone stimulation induces glucocorticoid receptormediated pulses of gene transcription. Nat Cell Biol. (2009) 11:1093-102. doi: $10.1038 /$ ncb1922

20. Biddie SC, Conwaycampbell BL, Lightman SL. Dynamic regulation of glucocorticoid signalling in health and disease. Rheumatology (2012) 51:40312. doi: 10.1093/rheumatology/ker215

21. Li Y, Wang L, Zhou L, Song Y, Ma S, Yu C, et al. Thyroid stimulating hormone increases hepatic gluconeogenesis via CRTC2. Mol Cell Endocrinol. (2017) 446:70-80. doi: 10.1016/j.mce.2017.02.015

22. Galofré JC, Pujante P, Abreu C, Santos S, Guillen-Grima F, Frühbeck G, et al. Relationship between thyroid-stimulating hormone and insulin in euthyroid obese men. Ann. Nutr Metab. (2008) 53:188-94. doi: 10.1159/000172981

23. Brent GA. Clinical practice. Graves' disease. New Engl J Med. (2008) 358:2594-605. doi: 10.1056/NEJMcp0801880

24. Suh JH, Sieglaff DH, Zhang A, Xia X, Cvoro A, Winnier GE, et al. SIRT1 is a Direct coactivator of thyroid hormone receptor $\beta 1$ with gene-Specific actions. PLoS ONE (2013) 8:e70097. doi: 10.1371/journal.pone.0070097

25. Bankir L, Bichet DG, Morgenthaler NG. Vasopressin: physiology, assessment and osmosensation. J Int Med. (2017) 282:284-97. doi: 10.1111/joim.12645

26. Melander O. Vasopressin, from regulator to disease predictor for diabetes and cardiometabolic risk. Ann Nutr Metab. (2016) 68(Suppl. 2):24-8. doi: 10.1159/000446201

27. Abu-Basha EA, Yibchok-Anun S, Hsu WH. Glucose dependency of arginine vasopressin-induced insulin and glucagon release from the perfused rat pancreas. Metabolism (2002) 51:1184-90. doi: 10.1053/meta.2002.34052

28. Gonzalez-Regueiro JA, Moreno-Castaneda L, Uribe M, Chavez-Tapia NC. The role of bile acids in glucose metabolism and their relation with diabetes. Ann Hepatol. (2017) 16(Suppl. 1):16-21. doi: 10.5604/01.3001.0010.5672

29. Yamagata K, Daitoku H, Shimamoto Y, Matsuzaki H, Hirota K, Ishida J, et al. Bile acids regulate gluconeogenic gene expression via small heterodimer partner-mediated repression of hepatocyte nuclear factor 4 and Foxo1. J Biol Chem. (2004) 279:23158-65. doi: 10.1074/jbc.M314322200

30. Ma K, Saha PK, Chan L, Moore DD. Farnesoid X receptor is essential for normal glucose homeostasis. J Clin Invest. (2006) 116:1102-9. doi: 10.1172/JCI25604

31. Potthoff MJ, Boney-Montoya J, Choi M, He T, Sunny NE, Satapati $\mathrm{S}$, et al. FGF15/19 regulates hepatic glucose metabolism by inhibiting the CREB-PGC-1alpha pathway. Cell Metab. (2011) 13:729-38. doi: 10.1016/j.cmet.2011.03.019

32. Kwok RPS, Laurance ME, Lundblad JR, Goldman PS, Shih H, Connor LM, et al. Control of CAMP-regulated enhancers by the viral transactivator Tax through CREB and the co-activator CBP. Nature (1996) 380:642-6. doi: $10.1038 / 380642 \mathrm{a} 0$
33. Yao W, Wang T, Huang F. p300/CBP as a key nutritional sensor for hepatic energy homeostasis and liver fibrosis. Biomed Res Int. (2018) 2018:8168791. doi: 10.1155/2018/8168791

34. Haeusler RA, Kaestner KH, Accili D. FoxOs function synergistically to promote glucose production. J Biol Chem. (2010) 285:35245-8. doi: 10.1074/jbc.C110.175851

35. Paik JH, Kollipara R, Chu G, Ji H, Xiao Y, Ding Z, et al. FoxOs are lineage-restricted redundant tumor suppressors and regulate endothelial cell homeostasis. Cell (2007) 128:309-23. doi: 10.1016/j.cell.2006.12.029

36. Zhang W, Patil S, Chauhan B, Guo S, Powell DR, Le J, et al. FoxO1 regulates multiple metabolic pathways in the liver: effects on gluconeogenic, glycolytic, and lipogenic gene expression. J Biol Chem. (2006) 281:10105-17. doi: 10.1074/jbc.M600272200

37. Lu M, Wan M, Leavens KF, Chu Q, Monks BR, Fernandez S, et al. Insulin regulates liver metabolism in vivo in the absence of hepatic Akt and Foxol. Nat Med. (2012) 18:388-95. doi: 10.1038/nm.2686

38. Lin J, Wu PH, Tarr PT, Lindenberg KS, St-Pierre J, Zhang CY, et al. Defects in adaptive energy metabolism with CNS-linked hyperactivity in PGC-1 $\alpha$ null mice. Cell (2004) 119:121-35. doi: 10.1016/j.cell.2004.09.013

39. Iwasaki H. Impaired PRMT1 activity in the liver and pancreas of type 2 diabetic Goto-Kakizaki rats. Life Sci. (2009) 85:161-6. doi: 10.1016/j.lfs.2009.05.007

40. Kim H, Zheng Z, Walker PD, Kapatos G, Zhang K. CREBH maintains circadian glucose homeostasis by regulating hepatic glycogenolysis and gluconeogenesis. Mol Cell Biol. (2017) 37:e00048-17. doi: 10.1128/MCB.00048-17

41. Lee MW, Chanda D, Yang J, Oh H, Su SK, Yoon YS, et al. Regulation of hepatic gluconeogenesis by an ER-bound transcription factor, CREBH. Cell Metab. (2010) 11:331-9. doi: 10.1016/j.cmet.2010.02.016

42. Xu X, Hu J, Mcgrath BC, Cavener DR. GCN2 regulates the CCAAT enhancer binding protein beta and hepatic gluconeogenesis. Am J Physiol Endocrinol Metab. (2013) 305:E1007-17. doi: 10.1152/ajpendo.00063.2013

43. Lee YH, Sauer B, Johnson PF, Gonzalez FJ. Disruption of the c/ebp alpha gene in adult mouse liver. Mol Cell Biol. (1997) 17:6014-22. doi: 10.1128/MCB.17.10.6014

44. Qiao L, Macdougald OA, Shao J. CCAAT/enhancer-binding protein $\alpha$ mediates induction of hepatic phosphoenolpyruvate carboxykinase by p38 mitogen-activated protein kinase. J Biol Chem. (2006) 281:24390-7. doi: 10.1074/jbc.M603038200

45. Liu S, Croniger C, Arizmendi C, Haradashiba M, Ren J, Poli V, et al. Hypoglycemia and impaired hepatic glucose production in mice with a deletion of the C/EBPbeta gene. J Clin Invest. (1999) 103:207-13. doi: 10.1172/JCI4243

46. Choudhury M, Qadri I, Rahman SM, Schroeder-Gloeckler J, Janssen RC, Friedman JE. C/EBP $\beta$ is AMP kinase sensitive and up-regulates PEPCK in response to ER stress in hepatoma cells. Mol Cell Endocrinol. (2011) 331:102-8. doi: 10.1016/j.mce.2010.08.014

47. Mangelsdorf DJ, Thummel C, Beato M, Herrlich P, Schütz G, Umesono $\mathrm{K}$, et al. The nuclear receptor superfamily: the second decade. Cell (2000) 83:835-9. doi: 10.1016/0092-8674(95)90199-X

48. Li J, Ning G, Duncan SA. Mammalian hepatocyte differentiation requires the transcription factor HNF-4 $\alpha$. Genes Dev. (2000) 14:464-74. doi: $10.1101 /$ gad.14.4.464

49. Zhang M, Lv X, Li J, Meng Z, Wang Q, Chang W, et al. Sodium caprate augments the hypoglycemic effect of berberine via AMPK in inhibiting hepatic gluconeogenesis. Mol Cell Endocrinol. (2012) 363:122-30. doi: 10.1016/j.mce.2012.08.006

50. Liu NC, Lin WJ, Kim E, Collins LL, Lin HY, Yu IC, et al. Loss of TR4 orphan nuclear receptor reduces phosphoenolpyruvate carboxykinasemediated gluconeogenesis. Diabetes (2007) 56:2901-9. doi: 10.2337/db070359

51. Pei L, Castrillo A, Chen M, Hoffmann A, Tontonoz P. Induction of NR4A orphan nuclear receptor expression in macrophages in response to inflammatory stimuli. J Biol Chem. (2005) 280:29256-62. doi: 10.1074/jbc.M502606200

52. Pei L, Waki H, Vaitheesvaran B, Wilpitz DC, Kurland IJ, Tontonoz P. NR4A orphan nuclear receptors are transcriptional regulators of hepatic glucose metabolism. Nat Med. (2006) 12:1048-55. doi: 10.1038/nm1471

53. Kersten S. Integrated physiology and systems biology of PPAR $\alpha$. Mol Metab. (2014) 3:354-71. doi: 10.1016/j.molmet.2014.02.002 
54. Jo YS, Ryu D, Maida A, Wang X, Evans RM, Schoonjans K, et al. Phosphorylation of the nuclear receptor corepressor 1 by protein kinase B switches its corepressor targets in the liver in mice. Hepatology (2015) 62:1606-18. doi: 10.1002/hep.27907

55. Lu Y, Xiong X, Wang X, Zhang Z, Li J, Shi G, et al. Yin Yang 1 promotes hepatic gluconeogenesis through upregulation of glucocorticoid receptor. Diabetes (2013) 62:1064-73. doi: 10.2337/db12-0744

56. Zhang Y, Guan Q, Liu Y, Zhang Y, Chen Y, Chen J, et al. Regulation of hepatic gluconeogenesis by nuclear factor $Y$ transcription factor in mice. J Biol Chem. (2018) 293:7894-904. doi: 10.1074/jbc.RA117.000508

57. Cho YM, Kim TH, Lim S, Choi SH, Shin HD, Lee HK, et al. Type 2 diabetesassociated genetic variants discovered in the recent genome-wide association studies are related to gestational diabetes mellitus in the Korean population. Diabetologia (2009) 52:253-61. doi: 10.1007/s00125-008-1196-4

58. Oh KJ, Park J, Kim SS, Oh H, Choi CS, Koo SH. TCF7L2 modulates glucose homeostasis by regulating CREB- and FoxO1-dependent transcriptional pathway in the liver. PLoS Genet. (2012) 8:e1002986. doi: 10.1371/journal.pgen.1002986

59. Norton L, Abdul-Ghani MA, Winnier D, Mehta FF, Jenkinson CP, Defronzo RA. Chromatin occupancy of transcription factor 7-like 2 (TCF7L2) and its role in hepatic glucose metabolism. Diabetologia (2011) 54:3132-42. doi: 10.1007/s00125-011-2289-Z

60. Yi F, Brubaker PL, Jin T. TCF-4 mediates cell type-specific regulation of proglucagon gene expression by beta-catenin and glycogen synthase kinase-3beta. J Biol Chem. (2005) 280:1457-64. doi: 10.1074/jbc.M411 487200

61. Besseiche A, Riveline J, Gautier J, Breant B, Blondeau B. Metabolic roles of PGC- $1 \alpha$ and its implications for type 2 diabetes. Diabetes Metabol. (2015) 41:347-57. doi: 10.1016/j.diabet.2015.02.002

62. Herzig S, Long F, Jhala US, Hedrick S, Quinn R, Bauer A, et al. CREB regulates hepatic gluconeogenesis through the coactivator PGC-1. Nature (2001) 413:179-83. doi: 10.1038/35093131

63. Handschin C, Lin J, Rhee J, Peyer AK, Chin S, Wu PH, et al. Nutritional regulation of hepatic heme biosynthesis and porphyria through PGC-1 $\alpha$. Cell (2005) 122:505-15. doi: 10.1016/j.cell.2005.06.040

64. Koo SH, Satoh H, Herzig S, Lee C, Hedrick S, Kulkarni RN, et al. PGC-1 promotes insulin resistance in liver through PPAR- $\alpha$-dependent induction of TRB-3. Nat Med. (2004) 10:530-4. doi: 10.1038/nm1044

65. Patel K, Foretz M, Marion A, Campbell DG, Gourlay R, Boudaba $\mathrm{N}$, et al. The LKB1-salt-inducible kinase pathway functions as a key gluconeogenic suppressor in the liver. Nat Commun. (2014) 5:4535. doi: $10.1038 /$ ncomms5535

66. Wang Y, Vera L, Fischer WH, Montminy M. The CREB coactivator CRTC2 links hepatic ER stress and fasting gluconeogenesis. Nature (2009) 460:534-7. doi: $10.1038 /$ nature08111

67. Ravnskjaer K, Hogan MF, Lackey D, Tora L, Dent SY, Olefsky J, et al. Glucagon regulates gluconeogenesis through KAT2B- and WDR5-mediated epigenetic effects. J Clin Invest. (2013) 123:4318-28. doi: 10.1172/JC I69035

68. Wang Y, Inoue H, Ravnskjaer K, Viste K, Miller N, Liu Y, et al. Targeted disruption of the CREB coactivator Crtc2 increases insulin sensitivity. Proc Natl Acad Sci USA. (2010) 107:3087-92. doi: 10.1073/pnas.0914897107

69. Ogryzko VV, Schiltz RL, Russanova V, Howard BH, Nakatani Y. The transcriptional coactivators $\mathrm{p} 300$ and CBP are histone acetyltransferases. Cell (1996) 87:953-59. doi: 10.1016/S0092-8674(00)82001-2

70. Wondisford AR, Xiong L, Chang E, Meng S, Meyers DJ, Li M, et al. Control of foxol gene expression by co-activator P300. J Biol Chem. (2014) 289:4326-33. doi: 10.1074/jbc.M113.540500

71. Lee JM, Seo WY, Han HS, Oh KJ, Lee YS, Kim DK, et al. InsulinInducible SMILE inhibits hepatic gluconeogenesis. Diabetes (2016) 65:62-73. doi: $10.2337 / \mathrm{db} 15-0249$

72. Ehrlund A, Treuter E. Ligand-independent actions of the orphan receptors/corepressors DAX-1 and SHP in metabolism, reproduction and disease. J Steroid Biochem Mol Biol. (2012) 130:169-79. doi: 10.1016/j.jsbmb.2011.04.007

73. Lee JM, Seo WY, Song KH, Chanda D, Yong DK, Kim DK, et al. AMPK-dependent repression of hepatic gluconeogenesis via disruption of CREB.CRTC2 complex by orphan nuclear receptor small heterodimer partner. J Biol Chem. (2010) 285:32182-91. doi: 10.1074/jbc.M110.134890

74. Nedumaran B, Hong SY, Kim YH, Seo WY, Lee MW, Lee CH, et al. DAX1 acts as a novel corepressor of orphan nuclear receptor HNF4alpha and negatively regulates gluconeogenic enzyme gene expression. J Biol Chem. (2009) 284:27511-23. doi: 10.1074/jbc.M109.034660

75. Foretz M, Ancellin N, Andreelli F, Saintillan Y, Grondin P, Kahn A, et al. Short-term overexpression of a constitutively active form of AMP-activated protein kinase in the liver leads to mild hypoglycemia and fatty liver. Diabetes (2005) 54:1331-9. doi: 10.2337/diabetes.54.5.1331

76. Cool B, Zinker B, Chiou W, Kifle L, Cao N, Perham M, et al. Identification and characterization of a small molecule AMPK activator that treats key components of type 2 diabetes and the metabolic syndrome. Cell Metab. (2006) 3:403-16. doi: 10.1016/j.cmet.2006.05.005

77. Koo SH, Flechner L, Qi L, Zhang X, Screaton RA, Jeffries S, et al. The CREB coactivator TORC2 is a key regulator of fasting glucose metabolism. Nature (2005) 437:1109-11. doi: 10.1038/nature03967

78. Mihaylova MM, Vasquez DS, Ravnskjaer K, Denechaud PD, Yu RT, Alvarez JG, et al. Class IIa histone deacetylases are hormone-activated regulators of FOXO and mammalian glucose homeostasis. Cell (2011) 145:607-21. doi: 10.1016/j.cell.2011.03.043

79. Benziane B, Bjornholm M, Lantier L, Viollet B, Zierath JR, Chibalin AV. AMP-activated protein kinase activator A-769662 is an inhibitor of the $\mathrm{Na}(+)-\mathrm{K}(+)$-ATPase. Am J Physiol Cell Physiol. (2009) 297:C1554-66. doi: 10.1152/ajpcell.00010.2009

80. Moreno D, Knecht E, Viollet B, Sanz P. A76(9662) a novel activator of AMP-activated protein kinase, inhibits non-proteolytic components of the $26 \mathrm{~S}$ proteasome by an AMPK-independent mechanism. FEBS Lett. (2008) 582:2650-4. doi: 10.1016/j.febslet.2008.06.044

81. Foretz M, Hebrard S, Leclerc J, Zarrinpashneh E, Soty M, Mithieux G, et al. Metformin inhibits hepatic gluconeogenesis in mice independently of the LKB1/AMPK pathway via a decrease in hepatic energy state. J Clin Invest. (2010) 120:2355-69. doi: 10.1172/JCI40671

82. Cokorinos EC, Delmore J, Reyes AR, Albuquerque B, Kjobsted R, Jorgensen $\mathrm{NO}$, et al. Activation of skeletal muscle AMPK promotes glucose disposal and glucose lowering in non-human primates and mice. Cell Metab. (2017) 25:1147-59.e1110. doi: 10.1016/j.cmet.2017.04.010

83. Fullerton MD, Galic S, Marcinko K, Sikkema S, Pulinilkunnil T, Chen $\mathrm{ZP}$, et al. Single phosphorylation sites in Accl and Acc2 regulate lipid homeostasis and the insulin-sensitizing effects of metformin. Nat Med. (2013) 19:1649-54. doi: 10.1038/nm.3372

84. Di LA, Bedford MT. Histone arginine methylation. FEBS Lett. (2011) 585:2024-31. doi: 10.1016/j.febslet.2010.11.010

85. Yamagata K, Daitoku H, Takahashi Y, Namiki K, Hisatake K, Kako K, et al. Arginine methylation of FOXO transcription factors inhibits their phosphorylation by Akt. Mol Cell (2008) 32:221-31. doi: 10.1016/j.molcel.2008.09.013

86. Choi D, Oh KJ, Han HS, Yoon YS, Jung CY, Kim ST, et al. Protein arginine methyltransferase 1 regulates hepatic glucose production in a FoxOl-dependent manner. Hepatology (2012) 56:1546-56. doi: 10.1002/hep.25809

87. Krones-Herzig A, Mesaros A, Metzger D, Ziegler A, Lemke U, Bruning JC, et al. Signal-dependent control of gluconeogenic key enzyme genes through coactivator-associated arginine methyltransferase 1. J Biol Chem. (2006) 281:3025-9. doi: 10.1074/jbc.M509770200

88. $\mathrm{Xu} \mathrm{W}$, Chen $\mathrm{H}, \mathrm{Du} \mathrm{K}$, Asahara H, Tini $\mathrm{M}$, Emerson BM, et al. A transcriptional switch mediated by cofactor methylation. Science (2001) 294:2507-11. doi: 10.1126/science.1065961

89. Tsai WW, Niessen S, Goebel N, Yates JR III, Guccione E, Montminy M. PRMT5 modulates the metabolic response to fasting signals. Proc Natl Acad Sci USA. (2013) 110:8870-5. doi: 10.1073/pnas.1304602110

90. Kanamaluru D, Xiao Z, Fang S, Choi SE, Kim DH, Veenstra TD, et al. Arginine methylation by PRMT5 at a naturally occurring mutation site is critical for liver metabolic regulation by small heterodimer partner. Mol Cell Biol. (2011) 31:1540-50. doi: 10.1128/MCB.01212-10

91. Han HS, Jung CY, Yoon YS, Choi S, Choi D, Kang G, et al. Arginine methylation of CRTC2 is critical in the transcriptional control of hepatic 
glucose metabolism. Sci Signal. (2014) 7:ra19. doi: 10.1126/scisignal.20 04479

92. Martin C, Zhang Y. The diverse functions of histone lysine methylation. Nat Rev Mol Cell Biol. (2005) 6:838-49. doi: 10.1038/nrm1761

93. Mosammaparast N, Shi Y. Reversal of histone methylation: biochemical and molecular mechanisms of histone demethylases. Annu Rev Biochem. (2010) 79:155-79. doi: 10.1146/annurev.biochem.78.070907.103946

94. Culhane JC, Cole PA. LSD1 and the chemistry of histone demethylation. Curr Opin Chem Biol. (2007) 11:561-8. doi: 10.1016/j.cbpa.2007.07.014

95. Tsukada Y, Fang J, Erdjument-Bromage H, Warren ME, Borchers CH, Tempst P, et al. Histone demethylation by a family of JmjC domaincontaining proteins. Nature (2006) 439:811-6. doi: 10.1038/nature04433

96. Hall RK, Wang XL, George L, Koch SR, Granner DK. Insulin represses phosphoenolpyruvate carboxykinase gene transcription by causing the rapid disruption of an active transcription complex: a potential epigenetic effect. Mol Endocrinol. (2007) 21:550-63. doi: 10.1210/me.2006-0307

97. Pan D, Mao C, Zou T, Yao AY, Cooper MP, Boyartchuk V, et al. The histone demethylase Jhdm1a regulates hepatic gluconeogenesis. PLoS Genet. (2012) 8:e1002761. doi: 10.1371/journal.pgen.1002761

98. Pan D, Mao C, Wang YX. Suppression of gluconeogenic gene expression by LSD1-mediated histone demethylation. PLoS ONE (2013) 8:e66294. doi: 10.1371/journal.pone.0066294

99. Zhao S, Xu W, Jiang W, Yu W, Lin Y, Zhang T, et al. Regulation of cellular metabolism by protein lysine acetylation. Science (2010) 327:1000-4. doi: 10.1126/science.1179689

100. Choudhary C, Kumar C, Gnad F, Nielsen ML, Rehman M, Walther TC, et al. Lysine acetylation targets protein complexes and co-regulates major cellular functions. Science (2009) 325:834-40. doi: 10.1126/science.1 175371

101. Jiang W, Wang S, Xiao M, Lin Y, Zhou L, Lei Q, et al. Acetylation regulates gluconeogenesis by promoting PEPCK1 degradation via recruiting the UBR5 ubiquitin ligase. Mol Cell (2011) 43:33-44. doi: 10.1016/j.molcel.2011.04.028

102. Haberland M, Montgomery RL, Olson EN. The many roles of histone deacetylases in development and physiology: implications for disease and therapy. Nat Rev Genet. (2009) 10:32-42. doi: 10.1038/nrg2485

103. Crunkhorn S. Metabolic disease: new role for HDACs in glucose homeostasis. Nat Rev Drug Discov. (2011) 10:492. doi: 10.1038/nrd3483

104. Oiso H, Furukawa N, Suefuji M, Shimoda S, Ito A, Furumai R, et al. The role of class I histone deacetylase (HDAC) on gluconeogenesis in liver. Biochem Biophys Res Commun. (2011) 404:166-72. doi: 10.1016/j.bbrc.2010.11.086

105. Matsumoto M, Pocai A, Rossetti L, Depinho RA, Accili D. Impaired regulation of hepatic glucose production in mice lacking the forkhead transcription factor Foxol in liver. Cell Metab. (2007) 6:208-16. doi: 10.1016/j.cmet.2007.08.006

106. Winkler R, Benz V, Clemenz M, Bloch M, Foryst-Ludwig A, Wardat S, et al. Histone deacetylase 6 (HDAC6) is an essential modifier of glucocorticoid-induced hepatic gluconeogenesis. Diabetes (2012) 61:513-23. doi: $10.2337 / \mathrm{db} 11-0313$

107. Rodgers JT, Lerin C, Haas W, Gygi SP, Spiegelman BM, Puigserver P. Nutrient control of glucose homeostasis through a complex of PGC-1alpha and SIRT1. Nature (2005) 434:113-8. doi: 10.1038/nature03354

108. Nie Y, Erion DM, Yuan Z, Dietrich M, Shulman GI, Horvath TL, et al. STAT3 inhibition of gluconeogenesis is downregulated by SirT1. Nat Cell Biol. (2009) 11:492-500. doi: 10.1038/ncb1857

109. Erion DM, Yonemitsu S, Nie Y, Nagai Y, Gillum MP, Hsiao JJ, et al. SirT1 knockdown in liver decreases basal hepatic glucose production and increases hepatic insulin responsiveness in diabetic rats. Proc Natl Acad Sci USA. (2009) 106:11288-93. doi: 10.1073/pnas.0812931106

110. Liu Y, Dentin R, Chen D, Hedrick S, Ravnskjaer K, Schenk S, et al. A fasting inducible switch modulates gluconeogenesis via activator/coactivator exchange. Nature (2008) 456:269-73. doi: 10.1038/nature 07349

111. Canto C, Gerhart-Hines Z, Feige JN, Lagouge M, Noriega L, Milne JC, et al. AMPK regulates energy expenditure by modulating NAD+ metabolism and SIRT1 activity. Nature (2009) 458:1056-60. doi: 10.1038/nature 07813
112. Caton PW, Nayuni NK, Kieswich J, Khan NQ, Yaqoob MM, Corder R. Metformin suppresses hepatic gluconeogenesis through induction of SIRT1 and GCN5. J Endocrinol. (2010) 205:97-106. doi: 10.1677/JOE-09-0345

113. Kuang J, Chen L, Tang Q, Zhang J, Li Y, He J. The role of Sirt6 in obesity and diabetes. Front. Physiol. (2018) 9:135. doi: 10.3389/fphys.2018.00135

114. Jing E, Emanuelli B, Hirschey MD, Boucher J, Lee KY, Lombard DB, et al. Sirtuin-3 (Sirt3) regulates skeletal muscle metabolism and insulin signaling via altered mitochondrial oxidation and reactive oxygen species production. Proc Natl Acad Sci USA. (2011) 108:14608-13. doi: 10.1073/pnas.1111308108

115. Jiang L, Xiong J, Zhan J, Yuan F, Tang M, Zhang C, et al. Ubiquitin-specific peptidase 7 (USP7)-mediated deubiquitination of the histone deacetylase SIRT7 regulates gluconeogenesis. J Biol Chem. (2017) 292:13296-311. doi: 10.1074/jbc.M117.780130

116. Hundal RS, Krssak M, Dufour S, Laurent D, Lebon V, Chandramouli $\mathrm{V}$, et al. Mechanism by which metformin reduces glucose production in type 2 diabetes. Diabetes (2000) 49:2063-9. doi: $10.2337 /$ diabetes.49.12.2063

117. Zhou G, Myers R, Li Y, Chen Y, Shen X, Fenyk-Melody J, et al. Role of AMPactivated protein kinase in mechanism of metformin action. J Clin Invest. (2001) 108:1167-74. doi: 10.1172/JCI13505

118. Shaw RJ, Lamia KA, Vasquez D, Koo SH, Bardeesy N, Depinho RA, et al. The kinase LKB1 mediates glucose homeostasis in liver and therapeutic effects of metformin. Science (2005) 310:1642-6. doi: 10.1126/science.1 120781

119. Cao J, Meng S, Chang E, Beckwith-Fickas K, Xiong L, Cole RN, et al. Low concentrations of metformin suppress glucose production in hepatocytes through AMP-activated protein kinase (AMPK). J Biol Chem. (2014) 289:20435-46. doi: 10.1074/jbc.M114.567271

120. He L, Wondisford FE. Metformin action: concentrations matter. Cell Metab. (2015) 21:159-62. doi: 10.1016/j.cmet.2015.01.003

121. Meng S, Cao J, He Q, Xiong L, Chang E, Radovick S, et al. Metformin activates AMP-activated protein kinase by promoting formation of the alphabetagamma heterotrimeric complex. J Biol Chem. (2015) 290:3793-802. doi: 10.1074/jbc.M114.604421

122. Zhang CS, Li M, Ma T, Zong Y, Cui J, Feng JW, et al. Metformin activates AMPK through the lysosomal pathway. Cell Metab. (2016) 24:5212. doi: 10.1016/j.cmet.2016.09.003

123. Johanns M, Lai YC, Hsu MF, Jacobs R, Vertommen D, Van Sande $J$, et al. AMPK antagonizes hepatic glucagon-stimulated cyclic AMP signalling via phosphorylation-induced activation of cyclic nucleotide phosphodiesterase 4B. Nat. Commun. (2016) 7:10856. doi: 10.1038/ncomms 10856

124. Hunter RW, Hughey CC, Lantier L, Sundelin EI, Peggie M, Zeqiraj E, et al. Metformin reduces liver glucose production by inhibition of fructose-1-6-bisphosphatase. Nat Med. (2018) 24:1395-406. doi: 10.1038/s41591-018-0159-7

125. Boudaba N, Marion A, Huet C, Pierre R, Viollet B, Foretz M. AMPK re-activation suppresses hepatic steatosis but its downregulation does not promote fatty liver development. EBio Med. (2018) 28:194-209. doi: 10.1016/j.ebiom.2018.01.008

126. Lin HZ, Yang SQ, Chuckaree C, Kuhajda F, Ronnet G, Diehl AM. Metformin reverses fatty liver disease in obese, leptin-deficient mice. Nat Med. (2000) 6:998-1003. doi: 10.1038/79697

127. Owen MR, Doran E, Halestrap AP. Evidence that metformin exerts its anti-diabetic effects through inhibition of complex 1 of the mitochondrial respiratory chain. Biochem J. (2000) 348(Pt 3):607-14. doi: $10.1042 /$ bj3480607

128. Hawley SA, Ross FA, Chevtzoff C, Green KA, Evans A, Fogarty S, et al. Use of cells expressing gamma subunit variants to identify diverse mechanisms of AMPK activation. Cell Metab. (2010) 11:554-65. doi: 10.1016/j.cmet.2010.04.001

129. Ouyang J, Parakhia RA, Ochs RS. Metformin activates AMP kinase through inhibition of AMP deaminase. J Biol Chem. (2011) 286:1-11. doi: 10.1074/jbc.M110.121806

130. Miller RA, Chu Q, Xie J, Foretz M, Viollet B, Birnbaum MJ. Biguanides suppress hepatic glucagon signalling by decreasing production of cyclic AMP. Nature (2013) 494:256-60. doi: 10.1038/nature 11808 
131. Madiraju AK, Erion DM, Rahimi Y, Zhang XM, Braddock DT, Albright RA, et al. Metformin suppresses gluconeogenesis by inhibiting mitochondrial glycerophosphate dehydrogenase. Nature (2014) 510:542-6. doi: 10.1038/nature13270

132. Madiraju AK, Qiu Y, Perry RJ, Rahimi Y, Zhang XM, Zhang D, et al. Metformin inhibits gluconeogenesis via a redox-dependent mechanism in vivo. Nat Med. (2018) 24:1384-94. doi: 10.1038/s41591-018$0125-4$

133. Baur JA, Birnbaum MJ. Control of gluconeogenesis by metformin: does redox trump energy charge? Cell Metab. (2014) 20:197-9. doi: 10.1016/j.cmet.2014.07.013
Conflict of Interest Statement: The authors declare that the research was conducted in the absence of any commercial or financial relationships that could be construed as a potential conflict of interest.

Copyright (c) 2019 Zhang, Yang, Chen and Su. This is an open-access article distributed under the terms of the Creative Commons Attribution License (CC BY). The use, distribution or reproduction in other forums is permitted, provided the original author(s) and the copyright owner(s) are credited and that the original publication in this journal is cited, in accordance with accepted academic practice. No use, distribution or reproduction is permitted which does not comply with these terms. 